\title{
CLEPS 1.0: A new protocol for cloud aqueous phase oxidation of VOC mechanisms
}

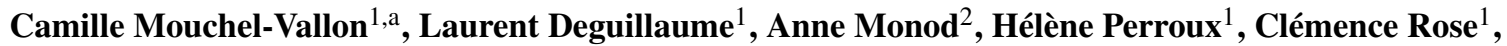 \\ Giovanni Ghigo $^{3}$, Yoann Long ${ }^{1, b}$, Maud Leriche ${ }^{4}$, Bernard Aumont ${ }^{5}$, Luc Patryl ${ }^{6}$, Patrick Armand ${ }^{6}$, and \\ Nadine Chaumerliac ${ }^{1}$ \\ ${ }^{1}$ Université Clermont Auvergne, CNRS Laboratoire de Météorologie Physique, 63000 Clermont-Ferrand, France \\ ${ }^{2}$ Aix Marseille Université, CNRS, LCE UMR 7376, 13331 Marseille, France \\ ${ }^{3}$ Dipartimento di Chimica, Universita di Torino, V. Giuria 7, 10125 Turin, Italy \\ ${ }^{4}$ Université de Toulouse, UPS, CNRS, Laboratoire d'Aérologie, 31400 Toulouse, France \\ ${ }^{5}$ LISA UMR CNRS 7583, Université Paris Est Créteil et Université Paris Diderot, Paris, France \\ ${ }^{6}$ CEA, DAM, DIF, 91297 Arpajon, France \\ ${ }^{a}$ now at: Wolfson Atmospheric Chemistry Laboratories, Department of Chemistry, University of York, \\ Heslington, York, YO10 5DD, UK \\ ${ }^{b}$ now at: Ramboll Environ, 155 rue Louis de Broglie, 13100 Aix-en-Provence, France
}

Correspondence to: Laurent Deguillaume (1.deguillaume@opgc.univ-bpclermont.fr) and Camille Mouchel-Vallon (camille.mouchel-vallon@york.ac.uk)

Received: 28 September 2016 - Discussion started: 17 October 2016

Revised: 24 February 2017 - Accepted: 27 February 2017 - Published: 29 March 2017

\begin{abstract}
A new detailed aqueous phase mechanism named the Cloud Explicit Physico-chemical Scheme (CLEPS 1.0) is proposed to describe the oxidation of water soluble organic compounds resulting from isoprene oxidation. It is based on structure activity relationships (SARs) which provide global rate constants together with branching ratios for $\mathrm{HO}^{\circ}$ abstraction and addition on atmospheric organic compounds. The GROMHE SAR allows the evaluation of Henry's law constants for undocumented organic compounds. This new aqueous phase mechanism is coupled with the MCM v3.3.1 gas phase mechanism through a mass transfer scheme between gas phase and aqueous phase. The resulting multiphase mechanism has then been implemented in a model based on the Dynamically Simple Model for Atmospheric Chemical Complexity (DSMACC) using the Kinetic PreProcessor (KPP) that can serve to analyze data from cloud chamber experiments and field campaigns.

The simulation of permanent cloud under low- $\mathrm{NO}_{x}$ conditions describes the formation of oxidized monoacids and diacids in the aqueous phase as well as a significant influence on the gas phase chemistry and composition and
\end{abstract}

shows that the aqueous phase reactivity leads to an efficient fragmentation and functionalization of organic compounds.

\section{Introduction}

Clouds favor chemical reactions that would not occur in the gas phase or at a rate much slower than in the aqueous phase (Epstein and Nizkorodov, 2012; Herrmann, 2003; Herrmann et al., 2015). Reactivity in clouds is due to (1) highly enhanced photochemical processes in cloud droplets; (2) faster aqueous phase reactions than in clear sky, some of which do not occur in the gas phase, especially those involving ions and hydration; and (3) possible interactions between the aqueous phase and particulate phase. Clouds can also be responsible for secondary organic aerosol (SOA) formation and ageing. However, aqueous phase processes suffer from large uncertainties. Blando and Turpin (2000) first proposed clouds as a source of SOAs. Recent field measurements (Kaul et al., 2011; Lee et al., 2012, 2011), experimental work (Brégonzio-Rozier et al., 2016) and modeling studies (Ervens, 2015; Ervens et al., 2011) have 
shown that aqueous phase processes could lead to SOA formation on the same order of magnitude as gas phase processes. The contribution of cloud and fog processes to SOA formation is firstly indirect, through the effects of cloud chemistry on the oxidant budget. Gas phase reactivity of volatile organic compounds (VOCs) is controlled by daytime HO oxidation, and it has been shown that phase separation of its precursors in clouds plays a significant role in the budget of this oxidant (Herrmann et al., 2015). Secondly, cloud and fog processes act directly on SOA sinks and sources. Dissolution and processing of organic vapor in the aqueous phase can lead to the formation and destruction of SOA precursors through accretion (i.e., carbon-carbon bond formation) and oxidation processes. These processes may compete in the aqueous phase (Kirkland et al., 2013; Renard et al., 2015), simultaneously acting as the source (through oligomerization and functionalization reactions) and sink (through fragmentation reactions) of SOAs. To elucidate the contribution of accretion and oxidation to the budget of SOA precursors, the most recent studies on the topic have focused on the modeling and measuring of accretion processes (Ervens et al., 2015). However, equivalent knowledge of aqueous oxidation is needed because oxidation processes may control the availability of organic compounds and radicals to form accretion products. In this work, we therefore focus on aqueous oxidation processes, especially the competition between fragmentation and functionalization.

Competition between fragmentation and functionalization processes has been identified as a major factor in the production of SOA in the gas phase (Donahue et al., 2012; Jimenez et al., 2009). To better represent these processes in clouds, detailed multiphase mechanisms are needed. A new mechanism, the Cloud Explicit Physicochemical Scheme (CLEPS 1.0), including organic compounds up to $\mathrm{C} 4$, has been developed under low- $\mathrm{NO}_{x}(<1 \mathrm{ppbv})$ and cloudy conditions and uses recent available laboratory data and empirical estimation methods. Then it is implemented in a box model including gas phase chemistry and kinetic mass transfer of soluble species between the gas phase and cloud droplets. It will be described in detail and finally compared with the same kind of mechanisms such as CAPRAM (Herrmann et al., 2005; Tilgner and Herrmann, 2010; Whalley et al., 2015) to highlight new features that have been proposed to create an explicit aqueous phase oxidation mechanism to accurately represent the various oxidation pathways of organic matter.

\section{Overview of the CLEPS chemical mechanism}

The aqueous phase oxidation mechanism originally relied on inorganic chemistry (see Deguillaume et al., 2004; Leriche et al., 2007) and on the oxidation of several organic $C_{1}$ and $C_{2}$ species, including photo-oxidation of iron complexes with oxalic acid (Long et al., 2013). The inorganic mechanism simulates the redox processes involved in the evolution of $\mathrm{H}_{x} \mathrm{O}_{y}$, sulfur, nitrogen, halogens (Leriche et al., 2000, 2003) and transition metal ions (TMIs; Deguillaume et al., 2004). A special emphasis is given to the latter, as the speciation of TMIs is believed to drive the evolution of aqueous phase oxidants $\left(\mathrm{H}_{2} \mathrm{O}_{2}, \mathrm{HO}, \mathrm{HO}_{2} / \mathrm{O}_{2}^{-}\right.$; Deguillaume et al., 2005) (see Reactions R14-R95 in the mechanism tables).

In the present study, the CLEPS mechanism is extended to the oxidation of $\mathrm{C}_{1-4}$ precursors and follows the protocol described in detail in Sect. 3. Although isoprene is not significantly dissolved in the atmospheric aqueous phase, its oxidation products are considered (methylgyoxalMGLY, glyoxal-GLY, acrolein-ACR, methacrolein-MACR, methylvinylketone-MVK) and are transferred into the aqueous phase according to their solubility and reactivity in the aqueous phase.

For each species and its oxidation products, the CLEPS mechanism describes the oxidation of $\mathrm{HO}$ (Sect. 3.1.3) and $\mathrm{NO}_{3}$ (Sect. 3.1.4) and the explicit evolution of the produced peroxyl radicals (Sect. 3.2). When rate constants are available, the reactivity of organic compounds with other oxidants $\left(\mathrm{SO}_{4}^{--}, \mathrm{Cl}_{2}^{--}\right.$, etc.) is also addressed (Sect. 3.1.5). Hydration (Sect. 3.1.1) and dissociation (Sect. 3.1.2) equilibria are, respectively, considered for carbonyl and carboxylic functions.

Moreover, recent developments in empirical estimates of kinetic and thermodynamic parameters (e.g., rate constants, Henry's law constants) for aqueous phase chemistry (Doussin and Monod, 2013; Minakata et al., 2009; Monod and Doussin, 2008; Raventos-Duran et al., 2010) are included in the CLEPS mechanism. These structure activity relationships (SARs) are based on experimental data and rely on robust hypotheses about the rate constants (Sect. 3.1.3.2) and equilibrium constants (Sects. 3.1.1 and 3.1.2) of species that are not documented in the literature. For instance, SARs can provide estimations of the branching ratios between the different oxidation pathways with $\mathrm{HO}$ radicals (Doussin and Monod, 2013; Minakata et al., 2009; Sect. 3.1.3.3).

The mechanism currently includes 850 aqueous reactions and 465 equilibria. Inorganic reactivity is described for 67 chemical species (e.g., TMIs, $\mathrm{H}_{x} \mathrm{O}_{y}$, sulfur species, nitrogen species and chlorine). For organic compounds, 87 chemical species are considered in the mechanism, leading to 657 chemical forms (when considering their various products as hydrated forms, anionic forms and radicals). The mechanism tables are available in the Supplement. 


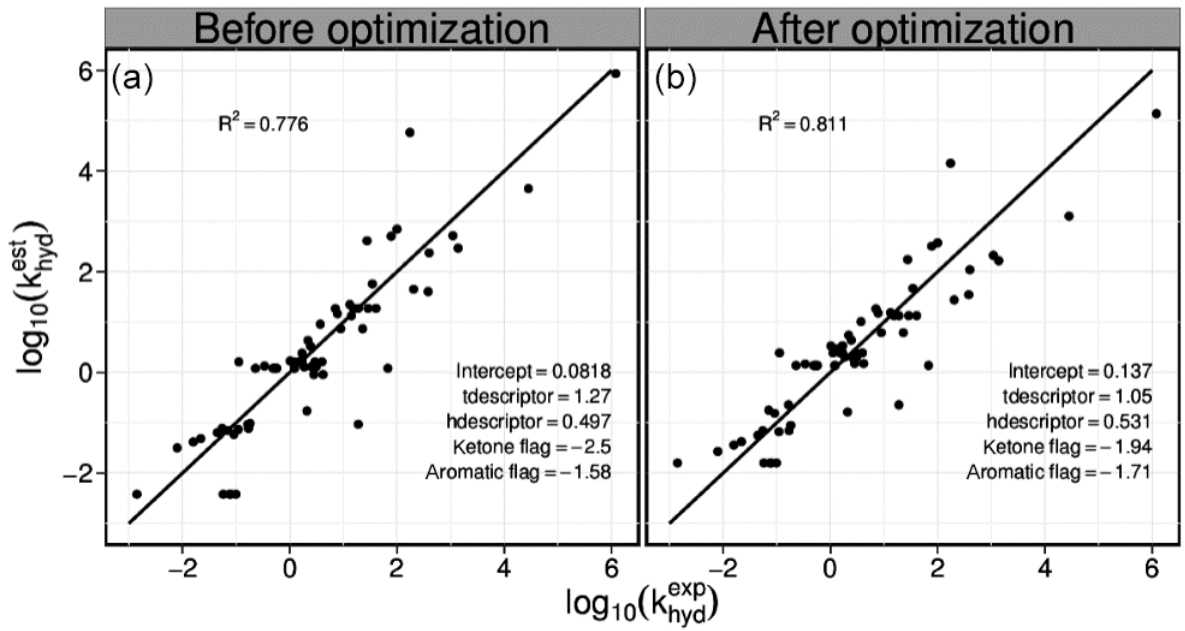

Figure 1. Scatterplots of the estimated $\log \left(K_{\text {hyd }}\right)$ using the SAR from Raventos-Duran et al. (2010) versus the experimental $\log \left(K_{\text {hyd }}\right)$, before (a) and after (b) the optimization for carboxylates. Values for the optimized descriptors are shown on the bottom right of each panel. The values chosen before the optimization are taken from Raventos-Duran et al. (2010). The line is the $y=x$ line.

\section{Development of the CLEPS aqueous phase mechanism}

\subsection{Non-radical organic species}

\subsubsection{Hydration equilibria}

Carbonyls, i.e., aldehydes and less likely ketones, may undergo hydration leading to the formation of a gem-diol form:

$>\mathrm{CO}+\mathrm{H}_{2} \mathrm{O} \stackrel{\mathrm{K}_{\text {hyd }}}{\longleftrightarrow}>\mathrm{C}(\mathrm{OH})(\mathrm{OH})$.

$K_{\text {hyd }}$ (dimensionless) is the hydration constant and is defined as

$\mathrm{K}_{\mathrm{hyd}}=\frac{>\mathrm{C}(\mathrm{OH})(\mathrm{OH})}{>\mathrm{CO}}$.

There are 30 carbonyl species in the mechanism. Most of the $\mathrm{C}_{1-2}$ species are well known and data are available in the literature. However, there is a lack of data for $\mathrm{C}_{3-4}$ species, and empirical estimates must be performed.

To the best of our knowledge, there is only one SAR available to estimate hydration constants (Raventos-Duran et al., 2010); it is provided by the GROMHE (GROup contribution Method for Henry's law Estimate) SAR for Henry's law constants. This SAR is based on five descriptors and is optimized on a dataset comprising 61 species. Raventos-Duran et al. (2010) defined a global descriptor, "tdescriptor", to represent functional group interactions with the sum of the so-called sigma Taft values ( $\sigma^{*}$, e.g., Perrin et al., 1981). Similarly, "hdescriptor" is a global descriptor representing the inductive effect of functional groups attached to an aromatic ring through the sum of the meta-, para- and ortho-Hammett sigma values $\left(\sigma_{\mathrm{m}}, \sigma_{\mathrm{p}}\right.$ and
Table 1. Experimental hydration constants for carboxylate species.

\begin{tabular}{|c|c|c|}
\hline Species & $K_{\text {hyd }}$ & References \\
\hline $\begin{array}{l}\text { Glyoxylate } \\
\mathrm{CH}(=\mathrm{O}) \mathrm{C}(=\mathrm{O})\left(\mathrm{O}^{-}\right)\end{array}$ & 67 & Tur'yan (1998) \\
\hline $\begin{array}{l}\text { Monoethyl oxaloacetate } \\
\mathrm{CH}_{3} \mathrm{CH}_{2}-\mathrm{O}- \\
\mathrm{C}(=\mathrm{O}) \mathrm{C}(=\mathrm{O}) \mathrm{CH}_{2} \mathrm{C}(=\mathrm{O})\left(\mathrm{O}^{-}\right)\end{array}$ & 3.125 & $\begin{array}{l}\text { Kozlowski and Zuman } \\
\text { (1987) }\end{array}$ \\
\hline $\begin{array}{l}\text { Pyruvate } \\
\mathrm{CH}_{3} \mathrm{C}(=\mathrm{O}) \mathrm{C}(=\mathrm{O})\left(\mathrm{O}^{-}\right)\end{array}$ & 0.0572 & Pocker et al. (1969) \\
\hline $\begin{array}{l}\alpha \text {-ketobutyrate } \\
\mathrm{CH}_{3} \mathrm{CH}_{2} \mathrm{C}(=\mathrm{O}) \mathrm{C}(=\mathrm{O})\left(\mathrm{O}^{-}\right)\end{array}$ & 0.08 & $\begin{array}{l}\text { Cooper and Redfield } \\
\text { (1975) }\end{array}$ \\
\hline $\begin{array}{l}\alpha \text {-ketoisovalerate } \\
\mathrm{CH}_{3} \mathrm{C}\left(\mathrm{CH}_{3}\right) \mathrm{C}(=\mathrm{O}) \mathrm{C}(=\mathrm{O})\left(\mathrm{O}^{-}\right)\end{array}$ & 0.075 & $\begin{array}{l}\text { Cooper and Redfield } \\
\text { (1975) }\end{array}$ \\
\hline $\begin{array}{l}\beta \text {-fluoropyruvate } \\
\mathrm{CH}_{2}(\mathrm{~F}) \mathrm{C}(=\mathrm{O}) \mathrm{C}(=\mathrm{O})\left(\mathrm{O}^{-}\right)\end{array}$ & 19 & Hurley et al. (1979) \\
\hline
\end{tabular}

$\sigma_{0}$, respectively; e.g., Perrin et al., 1981; for more details see Raventos-Duran et al., 2010). It is applied for all stable carbonyl species when a measured value is not available. However, this method was originally developed only for stable non-ionic species.

In the present study, the SAR is extended to anionic species. The descriptors have been optimized to include the Taft and Hammett sigma values for the carboxylate moieties $\left(\sigma^{*}\left(-\mathrm{CO}\left(\mathrm{O}^{-}\right)\right)=-1.06, \sigma_{\mathrm{m}}\left(-\mathrm{CO}\left(\mathrm{O}^{-}\right)\right)=0.09\right.$, $\sigma_{\mathrm{p}}\left(-\mathrm{CO}\left(\mathrm{O}^{-}\right)\right)=-0.05$ and $\sigma_{\mathrm{o}}\left(-\mathrm{CO}\left(\mathrm{O}^{-}\right)\right)=-0.91 ;$ Perrin et al., 1981). The database from Raventos-Duran et al. (2010) has been extended to carboxylate species with measured values available in the literature (Table 1). Following the same method as Raventos-Duran et al. (2010), multiple linear regression optimization is performed by minimizing the sum 
of squared errors (SSE):

$\mathrm{SSE}=\sum_{i=1}^{n}\left(\log K_{\mathrm{hyd}, \mathrm{est}}-\log K_{\mathrm{hyd}, \exp }\right)^{2}$,

where $n$ is the number of experimental values in the database $(n=65)$, including both the values compiled and taken into account by Raventos-Duran et al. (2010) and the new carboxylate values. Figure 1 shows both the previous and updated values of the descriptors and the performance of the SAR. The new optimization for carboxylate compounds modifies the descriptors by at most $50 \%$ for the intercept. The other descriptors vary from $1 \%$ ("hdescriptor") to $18 \%$ ("ketone flag") of their initial values. There is greater uncertainty associated with this new optimization; the root mean square error $\left(\mathrm{RMSE}=\sqrt{\frac{1}{n} \sum_{i=1}^{n}\left(\log K_{\text {hyd,est }}-\log K_{\text {hyd,exp }}\right)^{2}}\right)$ is $0.61 \log$ units, which is higher than the RMSE $=0.47 \log$ units given in Raventos-Duran et al. (2010). However, the new optimization is still able to estimate $K_{\text {hyd }}$ within a factor of 4 (3 in Raventos-Duran et al., 2010).

Hydration data are not available in the literature for the peroxyl $\left(\mathrm{RO}_{2}^{\prime}\right)$ and acylperoxyl $\left(\mathrm{RC}(=\mathrm{O})\left(\mathrm{OO}^{*}\right)\right)$ radicals. However, there is no reason to ignore the hydration of these radicals. As a first approach, when data are not available, we assign to a given $\mathrm{RO}_{2}$ the hydration constant of its parent species. For example, for the radicals derived from glycolaldehyde, we have

$$
\begin{aligned}
& K_{\text {hyd }}\left(\mathrm{CH}_{2}(\mathrm{OH}) \mathrm{CO}\left(\mathrm{OO}^{\circ}\right)\right) \\
= & K_{\text {hyd }}\left(\mathrm{CH}(\mathrm{OH})\left(\mathrm{OO}^{\circ}\right) \mathrm{CHO}\right) \\
= & K_{\text {hyd }}\left(\mathrm{CH}_{2}(\mathrm{OH}) \mathrm{CHO}\right)=10 .
\end{aligned}
$$

The lack of experimental data does not allow validation of this hypothesis and excludes further extension of the Raventos-Duran et al. (2010) SAR. This approximation is likely valid when there are no or weak interactions between the peroxyl and carbonyl functions, i.e., when these functions are separated by several carbon atoms. This is also applied to short-chain hydrocarbons and acylperoxyl radicals since it is the only way to counteract the lack of experimental data. When new data become available, they can be easily implemented to replace our hypothesis.

\subsubsection{Acid dissociation equilibria}

To represent acid dissociation, the acidity constant $K_{\mathrm{A}}(\mathrm{M})$ is needed:

$\mathrm{CO}(\mathrm{OH}) \stackrel{K_{\mathrm{A}}}{\longleftrightarrow}-\mathrm{CO}\left(\mathrm{O}^{-}\right)+\mathrm{H}^{+}$.

The acidity constant $K_{\mathrm{A}}$ is defined by

$K_{\mathrm{A}}=\frac{\left[-\mathrm{CO}\left(\mathrm{O}^{-}\right)\right]\left[\mathrm{H}^{+}\right]}{[-\mathrm{CO}(\mathrm{OH})]}$.
In general, the $K_{\mathrm{A}}$ values are well documented for short-chain organic compounds $\left(\mathrm{C}_{1-2}\right)$. In the mechanism, each stable acid with one or two carbon atoms can be documented using an acidity constant from the literature. This is not the case for $\mathrm{C}_{3}$ and $\mathrm{C}_{4}$ species, especially multifunctional species. In the whole mechanism, there are 38 organic acids, 7 of which have a documented $K_{\mathrm{A}}$ value (see Equilibria Tables in the mechanism tables). Like the hydration constants, the acidity constants must therefore be empirically estimated. To obtain the estimates, we use a similarity criterion: if there are no data available in the literature for a given species, the acidity constant from the closest documented species with the same organic function in the $\alpha$ position from the carboxylic acid function is chosen. For example, the acidity constant for pyruvic acid (Lide and Frederikse, 1995) is attributed to 3-oxopyruvic acid because they both carry a ketone function next to the carboxylic acid function, i.e.,

$$
\begin{aligned}
& K_{\mathrm{A}}(\mathrm{CHOC}(=\mathrm{O}) \mathrm{CO}(\mathrm{OH})) \\
= & K_{\mathrm{A}}\left(\mathrm{CH}_{3} \mathrm{C}(=\mathrm{O}) \mathrm{CO}(\mathrm{OH})=10^{-2.4} .\right.
\end{aligned}
$$

Perrin et al. (1981) showed that the $\mathrm{pK}_{\mathrm{A}}$ values of aliphatic organic species are mostly influenced by the inductive effect of the organic function closest to the acidic function. Therefore, this first hypothesis should provide a good estimation of undetermined acidity constants.

Following the hydration constant treatment, the acidity constants for peroxyl radicals are initially taken from their parent species when experimental data are not documented. This assumption can be questioned, but very few measurements suggest that peroxyl radicals are more acidic than their parent species. Schuchmann et al. (1989) showed that the acetic acid peroxyl radical $\left(\mathrm{CH}_{2}\left(\mathrm{OO}^{\circ}\right) \mathrm{CO}(\mathrm{OH})\right)$ has a $\mathrm{pKa}=2.10$, whereas acetic acid has a $\mathrm{pKa}=4.76$, and they observed the same trend for the malonic acid peroxyl radical, which has a second $\mathrm{pKa}$ close to 3 compared to the malonic acid second $\mathrm{pKa}=5.7$. Therefore, the hydration constants from Schuchmann et al. (1989) are used in the mechanism, and the estimated hydration constants can be directly substituted by laboratory data when the data become available.

\subsubsection{Reaction with HO'}

\section{Mechanism}

For aliphatic organic compounds, $\mathrm{HO}^{\circ}$ reactivity proceeds by $\mathrm{H}$-abstraction, yielding an alkyl radical following what can occur in the gas phase (Herrmann et al., 2010, 2015):

$\mathrm{RH}+\mathrm{HO}^{\cdot} \longrightarrow \mathrm{R}^{\cdot}+\mathrm{H}_{2} \mathrm{O}$.

If the compound bears a $\mathrm{C}=\mathrm{C}$ double bond, the addition is favored:

$>\mathrm{C}=\mathrm{C}<+\mathrm{HO}^{\circ} \longrightarrow \mathrm{C}(\mathrm{OH})-\mathrm{C}<$. 
In addition to the gas phase like pathways described above, it may be possible for $\mathrm{HO}$ to undergo electron transfer in the presence of anions, especially carboxylate compounds (von Sonntag and Schuchmann, 1997):

$$
-\mathrm{CO}\left(\mathrm{O}^{-}\right)+\mathrm{HO}^{\circ} \longrightarrow-\mathrm{CO}\left(\mathrm{O}^{\circ}\right)+\mathrm{OH}^{-} .
$$

\section{Rate constants}

When rate constants of organic compound reactions with HO are available (see the review by Herrmann et al., 2010), they are used in the mechanism. In the CLEPS mechanism, for a total of 343 reactions with $\mathrm{HO}^{\prime}$, only 43 kinetic constants are available in the literature. Empirical estimates are thus required in most cases. The estimates are obtained using a recently developed SAR for the HO rate constant. Doussin and Monod (2013) described the extension of a SAR previously published in Monod and Doussin (2008) and Monod et al. (2005). This SAR provides a way to estimate the $\mathrm{H}$-abstraction rate constants for dissolved linear or cyclic alkanes, alcohols, carbonyls, carboxylic acids and carboxylates. This method includes descriptors that consider the effect of functional groups in the $\alpha$ - and $\beta$-positions of the abstracted hydrogen atom. For each considered organic moiety, Doussin and Monod (2013) optimized the $\alpha$ - and $\beta$ substitution factors. All estimates in the framework of the CLEPS mechanism are within the domain of validity of the Doussin and Monod (2013) SAR.

In the present study, the SAR was modified to account for the electron transfer on carboxylate compounds (Reaction R5). The relevance of this process was discussed by Doussin and Monod (2013). They found an electron transfer rate constant for $\alpha$-carbonyl carboxylate anions of $k\left(-\mathrm{C}(=\mathrm{O}) \mathrm{CO}\left(\mathrm{O}^{-}\right)\right)=2.1 \times 10^{8} \mathrm{M}^{-1} \mathrm{~s}^{-1}$, but it was not included in the original SAR due to the limited amount of experimental data. Their analysis was restricted to the $\alpha$ carbonyl bases (especially pyruvate and ketomalonate ions, for which electron transfer is dominant), due to the lack of abstractable $\mathrm{H}$-atoms. However, other carboxylate ions could undergo this type of reaction, even if electron transfer is of minor importance because of the faster $\mathrm{H}$-abstraction reactions. Therefore, in the present study, the SAR from Doussin and Monod (2013) has been modified to include the partial rate constant $k\left(-\mathrm{CO}\left(\mathrm{O}^{-}\right)\right)=2.1 \times 10^{8} \mathrm{M}^{-1} \mathrm{~s}^{-1}$ for each possible electron transfer reaction. This partial rate constant is affected by the $\alpha$ - and $\beta$-substitution factors in the same way as the original abstraction constants.

For all unsaturated species in the mechanism (i.e., methylvinylketone - MVK, methacrolein MACR, hydroxymethylvinylketone - MVKOH and hydroxymethacrolein - MACROH), the addition reaction rates have been evaluated following the literature and similarity criteria. For further developments involving unknown unsaturated compounds, the SAR from Minakata et al. (2009) should be used because it is the only method that can estimate partial addition rate constants on double bonds.

\section{Branching ratios}

Branching ratios are required to identify the most probable oxidation products. In previous mechanisms, the most labile $\mathrm{H}$-atom was empirically identified (e.g., using bond dissociation energy estimations), and the reaction was assumed to proceed exclusively via this $\mathrm{H}$-abstraction pathway (Ervens et al., 2003; Tilgner and Herrmann, 2010). This was the only hypothesis that could be considered because experimental data on the branching ratios in aqueous phase HO reactions are extremely scarce. The recent introduction of a group-contribution-based SAR (Doussin and Monod, 2013; Minakata et al., 2009) allows estimation of the contribution of each pathway to the global reactivity of each species. In our mechanism, for a given species the global reactivity rate is either provided by the literature or by an SAR, but the branching ratios are always obtained from SAR estimates.

Furthermore, for simplicity, a reduction hypothesis was considered in the mechanism for each stable species because explicitly writing all possible reactions would yield a huge number of chemical species. For example, Aumont et al. (2005) showed that the number of species formed in the gas phase for such explicit schemes increases exponentially with the size of the carbon skeleton of the parent species. One can assume based on Aumont et al. (2005) that, starting from a $\mathrm{C}_{4}$ precursor in the aqueous phase, the mechanism would require approximately $10^{3}$ distinct species involved in approximately $10^{4}$ reactions. Such a large set of species excludes the development of an aqueous phase oxidation mechanism by hand. A simple reduction scheme was therefore applied to mitigate this problem and an example is shown in Table 2 for three selected species. A Doussin and Monod (2013) SAR was applied to estimate the contribution of each possible pathway and to maintain at least $75 \%$ of the total reactivity. After the reduction is applied, the branching ratios are recalculated to maintain the global oxidation rate constant. This empirical reduction scheme helps to limit the number of species and reactions (657 different chemical forms (i.e., hydrates, anions and derived radicals) representing 87 stable species reacting in 673 oxidation reactions). This new aqueous phase mechanism then allows consideration of the most probable $\mathrm{H}$-abstraction reactions.

Table 2 shows that the Doussin and Monod (2013) SAR estimates often lead to a significant abstraction of the hydrogen atom bonded to the oxygen atom in the hydroxyl moiety. This mechanism has never been addressed in an atmospheric chemical scheme. This reactivity of the alcohol function towards the $\mathrm{HO}$ radical has been experimentally demonstrated by Asmus et al. (1973) for methanol, ethanol, tert-butanol and polyols. To determine whether this 
Table 2. Examples of the reduction scheme applied to estimate $\mathrm{HO}^{\circ}$ reaction branching ratios. $k_{i}$ values are the partial reaction rate corresponding to the labeled atoms $i$ in the left column.

\begin{tabular}{|c|c|c|c|c|c|c|}
\hline Molecule & $\begin{array}{l}\text { Estimated } \mathrm{H} \text {-abstraction rates } k_{i} \\
\text { on atom labeled } i \text { following Doussin } \\
\text { and Monod (2013) }\left(\mathrm{M}^{-1} \mathrm{~s}^{-1}\right)\end{array}$ & $\begin{array}{l}\text { Contribution } \\
\text { to the global } \\
\text { reaction rate }\end{array}$ & $\begin{array}{l}\text { Reactivity } \\
\text { threshold } \\
\text { considered }\end{array}$ & $\begin{array}{l}\text { Retained } \\
\text { pathways } \\
\text { contribution }\end{array}$ & $\begin{array}{r}\text { Scaled } \\
\text { constants }\end{array}$ & $\begin{array}{l}\text { Final estimated } \\
\text { rate }\left(\mathrm{M}^{-1} \mathrm{~s}^{-1}\right)\end{array}$ \\
\hline \multirow{2}{*}{ Hydrated glycolaldehyde } & $k_{1}=2.9 \times 10^{8}$ & $26 \%$ & \multirow{5}{*}{$\mathrm{C}_{2}: 90 \%$} & \multirow{5}{*}{$\begin{array}{l}\text { Yes } \\
\text { No } \\
\text { Yes } \\
\text { Yes }\end{array}$} & \multirow{5}{*}{$\begin{array}{r}28 \% \\
- \\
33 \% \\
39 \%\end{array}$} & $k_{1}=3.1 \times 10^{8}$ \\
\hline & $k_{2}=0.9 \times 10^{8}$ & \multirow{4}{*}{$\begin{array}{r}8 \% \\
30 \% \\
36 \%\end{array}$} & & & & - \\
\hline \multirow{3}{*}{${ }_{2}{ }_{2}^{\mathrm{HO}} \overbrace{\mathrm{OH}_{2}}^{\mathrm{H}_{2}}=\mathrm{CH}_{\mathrm{H}^{3}}^{\mathrm{OH}}$} & $k_{3}=3.4 \times 10^{8}$ & & & & & $k_{3}=3.6 \times 10^{8}$ \\
\hline & $k_{4}=4.0 \times 10^{8}$ & & & & & $k_{4}=4.3 \times 10^{8}$ \\
\hline & $k_{\text {Global }}=1.1 \times 10^{9}$ & & & & & $k_{\text {Global }}=1.1 \times 10^{9}$ \\
\hline \multirow{2}{*}{ 3-hydroxypropionaldehyde } & $k_{1}=1.5 \times 10^{9}$ & \multirow{5}{*}{$\begin{array}{r}36 \% \\
2 \% \\
2 \% \\
60 \%\end{array}$} & \multirow[t]{5}{*}{$\mathrm{C}_{3}: 75 \%$} & \multirow{5}{*}{$\begin{array}{l}\text { Yes } \\
\text { No } \\
\text { No } \\
\text { Yes }\end{array}$} & \multirow{5}{*}{$\begin{array}{r}38 \% \\
- \\
- \\
62 \%\end{array}$} & $k_{1}=1.5 \times 10^{9}$ \\
\hline & $k_{2}=9 \times 10^{7}$ & & & & & - \\
\hline \multirow{3}{*}{ 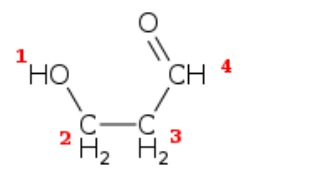 } & $k_{3}=7 \times 10^{7}$ & & & & & - \\
\hline & $k_{4}=2.5 \times 10^{9}$ & & & & & $k_{4}=2.6 \times 10^{9}$ \\
\hline & $k_{\text {Global }}=4.1 \times 10^{9}$ & & & & & $k_{\text {Global }}=4.1 \times 10^{9}$ \\
\hline \multirow[t]{5}{*}{ 2-hydroxy, 3-oxobutanoate } & $k_{1}=8.1 \times 10^{7}$ & $25 \%$ & \multirow[t]{5}{*}{$\mathrm{C}_{4}: 75 \%$} & \multirow{5}{*}{$\begin{array}{l}\text { Yes } \\
\text { No } \\
\text { Yes } \\
\text { Yes }\end{array}$} & \multirow{5}{*}{$\begin{array}{r}31 \% \\
- \\
33 \% \\
36 \%\end{array}$} & $k_{4}=1.0 \times 10^{8}$ \\
\hline & $k_{2}=6.1 \times 10^{7}$ & $19 \%$ & & & & - \\
\hline & $k_{3}=8.5 \times 10^{7}$ & $27 \%$ & & & & $k_{3}=1.1 \times 10^{8}$ \\
\hline & $k_{4}=9.2 \times 10^{7 *}$ & $29 \%$ & & & & $k_{4}=1.1 \times 10^{8}$ \\
\hline & $k_{\text {Global }}=3.2 \times 10^{8}$ & & & & & $k_{\text {Global }}=3.2 \times 10^{8}$ \\
\hline
\end{tabular}

* Electron transfer reaction.

reactivity could be extended to all the considered alcohol functions in our mechanism, we investigated whether the process appears thermodynamically feasible by calculating the relative reaction free energies (Gibbs energies) using density functional theory (DFT; see details and references in Supplement SM1). The thermodynamic values for the reaction enthalpies and Gibbs energies are calculated for the $\mathrm{H}$-abstraction by the $\mathrm{HO}$ radical from $\mathrm{C}$ and $\mathrm{O}$ atoms in the following molecules: acetaldehyde, propionaldehyde, glycolaldehyde, glyoxal, methylglyoxal, L-lactic acid and L-lactate. H-abstraction from hydrated aldehydes is also included in this study. The results (see Supplement SM2) show that $\mathrm{H}$-abstraction is thermodynamically favorable: the reaction enthalpies range from -14 to $-47 \mathrm{kcal} \mathrm{mol}^{-1}$ and the corresponding free energies range from -13 to $-47 \mathrm{kcal} \mathrm{mol}^{-1}$.

\subsection{Reaction with $\mathrm{NO}_{3}^{*}$}

$\mathrm{NO}_{3}$ is the main night-time oxidant in the gas phase. Although it plays a minor role under low- $\mathrm{NO}_{x}$ conditions (Ervens et al., 2003), $\mathrm{NO}_{3}$ chemistry has been taken into account in the protocol to make it versatile in the future. Previous modeling studies of aqueous phase reactivity expect the same characteristics for dissolved $\mathrm{NO}_{3}$ radicals (Tilgner and Herrmann, 2010). For this reason, we represent $\mathrm{NO}_{3}$ oxidation for each stable species in the mechanism.

\section{Mechanisms}

The mechanism of $\mathrm{NO}_{3}$ oxidation is similar to that of $\mathrm{HO}$ oxidation: the reactivity mainly proceeds via $\mathrm{H}$-abstraction of a labile hydrogen atom to form an alkyl radical and nitric acid:

$\mathrm{RH}+\mathrm{NO}_{3} \longrightarrow \mathrm{R}+\mathrm{HNO}_{3}$.

In this version of the mechanism, the addition of an $\mathrm{NO}_{3}$ radical to the $\mathrm{C}=\mathrm{C}$ double bond is not considered since insufficient data are available for these reactions and for the fate of the resulting organonitrate peroxyl radicals. However, organonitrate compounds were recently identified in the ambient aerosol (Garnes and Allen, 2002; Lee et al., 2016; Rollins et al., 2012). In addition to local emission sources, organonitrate compounds originate from the gas phase chemistry of VOCs under high $\mathrm{NO}_{x}$ conditions (Darer et al., 2011; Farmer et al., 2010; Heald et al., 2010; Paulot et al., 2009; Perring et al., 2013) followed by phase transfer and aqueous processing to the deliquescent aerosol and cloud aerosol phase (Nguyen et al., 2011) to form nitrates, alcohols or organosulfates, which contribute to SOA. In this study, we restricted the simulations to low- $\mathrm{NO}_{x}$ conditions to reduce 
the potential importance of organonitrate chemistry, which requires further experimental and modeling developments.

\section{Rate constants}

Data concerning $\mathrm{NO}_{3}$ reaction rates are available in the literature, mostly for $C_{1}$ and $C_{2}$ species (Exner et al., 1994; Gaillard de Sémainville et al., 2007, 2010; Herrmann et al., 2010, 2015). Again, empirical estimates are required to describe the oxidation by $\mathrm{NO}_{3}$ radicals when the data are unavailable.

For most $\mathrm{C}_{2-4}$ species, we estimate the $\mathrm{NO}_{3}$ rate constants using the similarity criteria. When an estimate is needed, we use the rate constant of a similar documented species. The primary focus is on the nature, number, and relative position of the organic functions. For example, the rate constant of 3hydroxypropionic acid with $\mathrm{NO}_{3}$ is estimated to be the same as the rate constant of lactic acid because both are $\mathrm{C}_{3}$ species with a carboxylic acid and a hydroxyl function:

$$
\begin{aligned}
& k\left(\mathrm{CH}_{2}(\mathrm{OH}) \mathrm{CH}_{2} \mathrm{CO}(\mathrm{OH})+\mathrm{NO}_{3}^{-}\right) \\
= & k\left(\mathrm{CH}_{3} \mathrm{CH}(\mathrm{OH}) \mathrm{CO}(\mathrm{OH})+\mathrm{NO}_{3}^{-}\right)=2.1 \times 10^{6} \mathrm{M}^{-1} \mathrm{~s}^{-1}
\end{aligned}
$$

(Gaillard de Sémainville et al., 2007).

\section{Branching ratios}

The branching ratios for $\mathrm{NO}_{3}$ oxidation are not available in the literature. As a first approach, we use branching ratios for the $\mathrm{NO}_{3}$ reactions that are identical to those estimated for $\mathrm{HO}$ reactions because $\mathrm{NO}_{3} \mathrm{H}$-abstraction proceeds following the same elementary mechanism as $\mathrm{HO} \mathrm{H}$ abstraction. $\mathrm{NO}_{3}$ radicals should be more sensitive to steric hindrance than $\mathrm{HO}^{\prime}$ radicals. However, without experimental evidence supporting this assumption, in our mechanism, $\mathrm{NO}_{3}$ radicals are unable to react via electron transfer and to abstract hydrogen atoms from $-\mathrm{OH}$ moieties. In these cases, electron transfer and $-\mathrm{OH}$ hydrogen abstraction are not included in the list of available $\mathrm{NO}_{3}$ reactions, and the remaining pathways are rescaled to $100 \%$. Therefore, for these types of reactions, the branching ratios for $\mathrm{NO}_{3}$ oxidation may differ from those for oxidation by $\mathrm{HO}$.

\subsubsection{Reaction with other oxidants}

Reaction rates with radicals other than $\mathrm{HO}$ or $\mathrm{NO}_{3}$ are available in the literature (Herrmann et al., 2015; Zellner et al., 1995). They mainly concern reactions of $C_{1-2}$ species with $\mathrm{Cl}_{2}^{--}, \mathrm{CO}_{3}^{--}, \mathrm{FeO}^{2+}$ and $\mathrm{SO}_{4}^{--}$. These reactions are included in the mechanism, and the branching ratios are based on the $\mathrm{HO}$ reaction branching ratios.

The reactivity of selected oxygenated organic species with $\mathrm{H}_{2} \mathrm{O}_{2}$ and $\mathrm{O}_{3}$, which was recently studied by Schöne and Herrmann (2014), is also included in the mechanism (see Reactions R586 and R590 in the mechanism tables). Although these rate constants are in the range of
$10^{-1}$ to $10^{1} \mathrm{M}^{-1} \mathrm{~s}^{-1}$, their impact is non-negligible under specific conditions, especially under low- $\mathrm{NO}_{x}$ conditions. Furthermore, reactions of $\mathrm{C}_{1-2}$ hydroperoxide compounds in Fenton-like reactions with $\mathrm{Fe}^{2+}$ have been studied by Chevallier et al. (2004) and are included in the mechanism (see Reactions R238 and R330 in the mechanism tables).

\subsubsection{Photolysis}

Most of the species considered in the mechanism are oxygenated and are likely to bear chromophore functional groups. To calculate the photolysis rate, the polychromatic absorption cross sections and quantum yields must be known. Again, the literature data concerning these subjects are scarce. Photolysis data are available for a few chromophore species: $\mathrm{H}_{2} \mathrm{O}_{2}$ (Graedel and Weschler, 1981; Zellner et al., 1990), carboxylate-iron(III) complexes (Faust and Zepp, 1993; Long et al., 2013; Weller et al., 2013a, b), and pyruvic acid (Reed Harris et al., 2014). Absorption crosssection and quantum yield data (preferably wavelengthdependent) are required to calculate photolysis frequencies. Pyruvic acid photolysis is not currently calculated in the model because only the photolysis frequencies are available in the literature.

Because the hydroperoxide $(-\mathrm{OOH})$ moiety is expected to be photosensitive, we include photolysis reactions for species bearing this organic function, using the cross sections and quantum yields measured for $\mathrm{H}_{2} \mathrm{O}_{2}$ (as in Leriche et al., 2003). For further improvement, photolysis reactions will be extended to other compounds when experimental data are available to determine which aqueous phase oxygenated compounds are photosensitive. Epstein et al. (2013) have shown that aqueous photolysis quantum yields are highly dependent on the type of molecule. Using similarity criteria to estimate photolysis rates in the aqueous phase may be too error prone. Furthermore their estimates also show that photolysis would efficiently compete with $\mathrm{HO}$ oxidation for very few photolabile species. If more data and reliable SAR become available on this subject, a mechanism generated using the present protocol would be the ideal tool to expand on the Epstein et al. (2013) study.

\subsection{Organic radicals}

\subsubsection{Alkyl radical $\mathrm{O}_{2}$ addition}

In dilute aqueous solution, alkyl radicals react with dissolved $\mathrm{O}_{2}$ to form peroxyl radicals:

$\mathrm{R}^{\cdot}+\mathrm{O}_{2} \longrightarrow \mathrm{R}\left(\mathrm{OO}^{\circ}\right)$.

Recent studies suggest that under high organic radical concentrations, this addition competes with the self- or cross-reactions of alkyl radicals, yielding high molecular weight molecules, such as oligomers (see Ervens et al., 2015; Griffith et al., 2013; Lim et al., 2013; Renard et al., 
2015). This competition can favor oligomerization if $\mathrm{O}_{2}$ is not readily available in the aqueous phase. In their bulk aqueous phase modeling study, Ervens et al. (2015) have shown that the aqueous phase under laboratory experiment conditions is not saturated with oxygen, leading to possible oligomerization. Their sensitivity studies however show that oxygen reached saturation in a few seconds for atmospheric deliquescent particles, likely because of a large surface-to-volume ratio. We follow the same hypothesis for cloud droplets. The review by Alfassi (1997) showed that the kinetics of the great majority of $\mathrm{R}+\mathrm{O}_{2}$ reactions are close to the diffusion limit, with rate constants of 2.0-4.0 $\times 10^{9} \mathrm{M}^{-1} \mathrm{~s}^{-1}$, and for non-carbon-centred radicals (such as nitrogen-centred radicals), significantly smaller rate constants are observed $\left(10^{7}\right.$ to $\left.10^{8} \mathrm{M}^{-1} \mathrm{~s}^{-1}\right)$. Hence, in our mechanism (which does not consider nitrogen-centred radicals) $\mathrm{H}$-abstraction and $\mathrm{O}_{2}$-addition steps are combined in a single step reaction due to the fast $\mathrm{O}_{2}$-addition reaction rate in the mechanism.

\subsubsection{Tetroxide formation and decomposition}

In general, a peroxyl radical reacts with itself or another peroxyl radical to form a tetroxide, which quickly decomposes (von Sonntag and Schuchmann, 1997). These reactions could be introduced to the mechanism by having each peroxyl radical react with every other peroxyl radical. With 363 peroxyl radicals in the mechanism, this would require more than 66000 reactions to be written to account for these cross-reactions. As a first approach, we restrict the mechanism to self-reactions. There are available methods to simplify the description of cross-reactions (Madronich and Calvert, 1990). These methods could be adapted for future versions of the mechanism.

The decomposition of tetroxide follows different pathways, depending on the nature of the initial peroxyl radical. Piesiak et al. (1984) proposed a mechanism for the evolution of the tetroxide formed after dimerization of $\beta$-hydroxyethylperoxyl radicals. Zegota et al. (1986) studied the self-reaction of the acetonylperoxyl radical and Schuchmann et al. (1985) explored the fate of the acetate peroxyl radical. The results of these studies have been extended in other experimental works for other peroxyl radicals (Liu et al., 2009; Monod et al., 2007; Poulain et al., 2010; Schaefer et al., 2012; Schöne et al., 2014; Stemmler and von Gunten, 2000; Zhang et al., 2010). We therefore implement peroxyl radical self-reactions following the similarity criteria detailed below.

For $\beta$-peroxycarboxylic acids $(>\mathrm{C}(\mathrm{OO}) \mathrm{C}(=\mathrm{O})(\mathrm{OH}))$ and their conjugated bases, we generalize the experimental results obtained by Schuchmann et al. (1985) for the acetate peroxyl radical $\left(\mathrm{CH}_{2}\left(\mathrm{OO}^{-}\right) \mathrm{C}(=\mathrm{O})\left(\mathrm{O}^{-}\right)\right)$. For this radical, the tetroxide is degraded through four pathways (Reaction R8):
$2 \mathrm{CH}_{2}\left(\mathrm{OO}^{\circ}\right) \mathrm{CO}\left(\mathrm{O}^{\circ}\right) \stackrel{k_{\text {global }}=7.5 \times 10^{7} \mathrm{M}^{-1} \mathrm{~s}^{-1}}{\longrightarrow}$

tetroxide $\longrightarrow$

$\begin{cases}\mathrm{CHOCO}\left(\mathrm{O}^{-}\right) & \text {branching ratio : } 30 \% \\ +\mathrm{CH}_{2}(\mathrm{OH}) \mathrm{CO}\left(\mathrm{O}^{-}\right)+\mathrm{O}_{2} & \\ 2 \mathrm{CHOCO}\left(\mathrm{O}^{-}\right)+\mathrm{H}_{2} \mathrm{O}_{2} & \text { branching ratio : } 30 \% \\ 2 \mathrm{HCHO}+2 \mathrm{CO}_{2} & \text { branching ratio : } 30 \% \\ +\mathrm{H}_{2} \mathrm{O}_{2}+2 \mathrm{OH}^{-} & \\ 2 \mathrm{CH}_{2}\left(\mathrm{O}^{-}\right) \mathrm{CO}\left(\mathrm{O}^{-}\right)+\mathrm{O}_{2} & \text { branching ratio : } 10 \%\end{cases}$

The four pathways retained in this work are the most important identified by Schuchmann et al. (1985). The sum of these pathways contributes $87 \%$ of the tetroxide decomposition, and each individual contribution is scaled to reach $100 \%$ overall.

The evolution of $\beta$-hydroxyperoxyl radicals $\left(>\mathrm{C}(\mathrm{OH}) \mathrm{C}\left(\mathrm{OO}^{\circ}\right)<\right)$ is represented by the experimental results obtained by Piesiak et al. (1984) for the $\beta$ hydroxyethylperoxyl radical $\left(\mathrm{CH}_{2}(\mathrm{OH}) \mathrm{CH}_{2}(\mathrm{OO})\right)$ (Reaction R9):

$2 \mathrm{CH}_{2}(\mathrm{OH}) \mathrm{CH}_{2}\left(\mathrm{OO}^{\circ}\right) \stackrel{k_{\text {global }}=1.0 \times 10^{8} \mathrm{M}^{-1} \mathrm{~s}^{-1}}{\longrightarrow}$

tetroxide $\longrightarrow$

$\begin{cases}\mathrm{CHOCH}_{2}(\mathrm{OH})+\mathrm{CH}_{2}(\mathrm{OH}) \mathrm{CH}_{2}(\mathrm{OH})+\mathrm{O}_{2} & 33 \% \\ 2 \mathrm{CHOCH}_{2}(\mathrm{OH})+\mathrm{H}_{2} \mathrm{O}_{2} & 50 \% \\ 2 \mathrm{CH}_{2}\left(\mathrm{O}^{\cdot}\right) \mathrm{CH}_{2}(\mathrm{OH})+\mathrm{O}_{2} & 17 \%\end{cases}$

The three pathways are reported to contribute $90 \%$ of the degradation of the tetroxide (Piesiak et al., 1984). The mechanism is restricted to these major pathways, and their individual contributions are scaled to reach $100 \%$ overall in our mechanism.

$\beta$-oxoperoxyl radicals $\left(-\mathrm{COC}\left(\mathrm{OO}^{-}\right)<\right)$are treated based on the studies of the acetonylperoxyl radical by Poulain et al. (2010) and Zegota et al. (1986) (Reaction R10):

$2 \mathrm{CH}_{3} \mathrm{COCH}_{2}\left(\mathrm{OO}^{\circ}\right) \stackrel{k_{\text {global }}=4.0 \times 10^{8} \mathrm{M}^{-1} \mathrm{~s}^{-1}}{\longrightarrow}$

tetroxide $\longrightarrow$

$\begin{cases}\mathrm{CH}_{3} \mathrm{COCH}_{2}(\mathrm{OH})+\mathrm{CH}_{3} \mathrm{COCHO}+\mathrm{O}_{2} & 20 \% \\ 2 \mathrm{CH}_{3} \mathrm{COCHO}_{2}+\mathrm{H}_{2} \mathrm{O}_{2} & 45 \% \\ 2 \mathrm{CH}_{3} \mathrm{COCH}_{2}\left(\mathrm{O}^{\circ}\right)+\mathrm{O}_{2} & 35 \%\end{cases}$

Except for the $\alpha$-hydroxyperoxyl and acylperoxyl radicals that are discussed in detail in the following subsections, peroxyl radicals that are not included in the above categories are addressed using the estimates from Monod et al. (2007) for the ethylperoxyl radical (Reaction R11): 
Table 3. Generalization of $\mathrm{HO}_{2}$ elimination rate constants for unknown species, following von Sonntag (1987).

\begin{tabular}{llrl}
\hline \multicolumn{2}{c}{ von Sonntag (1987) compilation } & \\
\cline { 1 - 2 } $\begin{array}{l}\text { 1st } \\
\text { substituent }\end{array}$ & $\begin{array}{l}\text { 2nd } \\
\text { substituent }\end{array}$ & $k\left(\mathrm{~s}^{-1}\right)^{*}$ & Generalization \\
\cline { 1 - 1 } & $\mathrm{H}$ & $<10$ & - \\
$\mathrm{H}$ & $\mathrm{CH}_{3}$ & 52 & $\begin{array}{l}\text { Primary peroxyl } \\
\text { radicals } \\
\end{array}$ \\
$\mathrm{H}$ & $\mathrm{CH}_{2}(\mathrm{OH})$ & 190 & $\begin{array}{l}\beta \text {-hydroxyperoxyl } \\
\text { radicals }\end{array}$ \\
$\mathrm{CH}_{3}$ & $\mathrm{CH}_{3}$ & 665 & $\begin{array}{l}\text { Secondary peroxyl } \\
\text { radicals }\end{array}$ \\
\hline
\end{tabular}

* $\mathrm{HO}_{2}$ elimination rate constant.

$2 \mathrm{CH}_{3} \mathrm{CH}_{2}\left(\mathrm{OO}^{\circ}\right) \stackrel{k_{\text {global }}=1.6 \times 10^{8} \mathrm{M}^{-1} \mathrm{~s}^{-1}}{\longrightarrow}$

tetroxide $\longrightarrow$

$\begin{cases}2 \mathrm{CH}_{3} \mathrm{CHO}+\mathrm{H}_{2} \mathrm{O}_{2} & 20 \% \\ 2 \mathrm{CH}_{3} \mathrm{CH}_{2} \mathrm{O}+\mathrm{O}_{2} & 80 \%\end{cases}$

The rate constant was measured by Herrmann et al. (1999). Schuchmann and von Sonntag (1984) estimated that the first pathway (aldehyde pathway) contributes $20 \%$ of the tetroxide decomposition. Studying the ethylperoxyl radical derived from the photooxidation of ethylhydroperoxyde, Monod et al. (2007) found that the second pathway (alkoxyl pathway) is more likely than the aldehyde pathway, in agreement with previous studies (Henon et al., 1997; von Sonntag and Schuchmann, 1997). Therefore, we attributed the remaining degradation of the tetroxide to the alkoxyl pathway.

\subsection{3 $\alpha$-hydroxyperoxyl $\mathrm{HO}_{2}^{;} / \mathrm{O}_{2}^{--}$elimination}

When a hydroxyl moiety is in the alpha position of the peroxyl function, the peroxyl radical likely undergoes $\mathrm{HO}_{2}$ elimination:

$>\mathrm{C}(\mathrm{OH})\left(\mathrm{OO}^{\circ}\right) \longrightarrow>\mathrm{C}=\mathrm{O}+\mathrm{HO}_{2}^{\circ}$

and an $\mathrm{O}_{2}^{-}$elimination following a basic catalysis (Zegota et al., 1986):

$>\mathrm{C}(\mathrm{OH})\left(\mathrm{OO}^{\circ}\right)+\mathrm{OH}^{-} \longrightarrow>\mathrm{C}=\mathrm{O}+\mathrm{O}_{2}^{--}+\mathrm{H}_{2} \mathrm{O}$.

von Sonntag (1987) showed that the $\mathrm{HO}_{2}$ elimination rate constant is dependent on the nature of the substituent attached to the carbon atom. Following this study, we generalized the $\mathrm{HO}_{2}$ elimination rate constants for unknown species using available experimental values. The generalization rules are detailed in Table 3 .

In the case of $\alpha$-dihydroxy-peroxyl compounds $\left(-\mathrm{C}(\mathrm{OH})(\mathrm{OH})\left(\mathrm{OO}^{\circ}\right)\right)$, McElroy and Waygood (1991) showed that $\mathrm{HC}(\mathrm{OH})(\mathrm{OH})(\mathrm{OO})$ decays with a rate constant $k>10^{6} \mathrm{~s}^{-1}$. Without additional estimates of $\mathrm{HO}_{2}$ elimination, we apply the same elimination rate constant of $k=10^{6} \mathrm{~s}^{-1}$ for all $\alpha$-dihydroxy-peroxyl compounds. Ilan et al. (1976) and Neta et al. (1990) provided an $\mathrm{O}_{2}^{--}$elimination rate constant for the 2, $\alpha$-hydroxypropylperoxyl radical $\left(k\left(\mathrm{CH}_{3} \mathrm{C}(\mathrm{OH})(\mathrm{OO}) \mathrm{CH}_{3}+\mathrm{OH}^{-}\right)=5.2 \times 10^{9} \mathrm{M}^{-1} \mathrm{~s}^{-1}\right)$ and the $\alpha$-hydroxyethylperoxyl radical $\left(k\left(\mathrm{CH}_{3} \mathrm{CH}(\mathrm{OH})\right.\right.$ $\left.\left.(\mathrm{OO})+\mathrm{OH}^{-}\right)=4.0 \times 10^{9} \mathrm{M}^{-1} \mathrm{~s}^{-1}\right)$. Given the high concentrations of $\mathrm{OH}^{-}$in water, these reactions are expected to be fast and should not be limiting steps. Therefore, an arbitrary rate constant $k=4.0 \times 10^{9} \mathrm{M}^{-1} \mathrm{~s}^{-1}$, close to the measured rate constants, is assigned to each elimination reaction.

As shown in Table $3, \mathrm{HO}_{2}$ elimination is a fast process, with an associated lifetime ranging from $1.5 \times 10^{-3}$ to $0.1 \mathrm{~s}$. In our simulation (see Sect. 6) the high range of concentrations for peroxyl radicals is around $10^{-10} \mathrm{M}$ for the peroxyl radical derived from glyoxal; tetroxide formation therefore occurs on a timescale of approximately $50 \mathrm{~s}$. Therefore, tetroxide formation and its subsequent decomposition are not considered for $\alpha$-hydroxyperoxyl radicals, and only direct decomposition is included in the mechanism.

\subsubsection{Acylperoxyl decarboxylation}

Acylperoxyl radicals $\left(-\mathrm{CO}\left(\mathrm{OO}^{\circ}\right)\right)$ are treated like standard peroxyl radicals (see Reaction R11) for which only the alkoxyl formation pathway is considered due to the lack of an $\mathrm{H}$-atom on the peroxyl radical. For the acylperoxyl derived from propionaldehyde, this gives

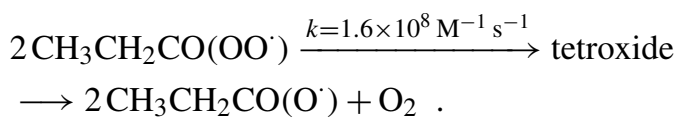

(R14)

The acylalkoxyl radical undergoes $\mathrm{C}-\mathrm{C}$ bond scission and yields $\mathrm{CO}_{2}$, accounting for the expected decarboxylation of the acylperoxyl radical.

\subsubsection{Alkoxyl radicals}

Alkoxyl radicals ( $\mathrm{RO}^{\circ}$ ) are formed after the decomposition of a tetroxide or after the $\mathrm{H}$-abstraction from $\mathrm{a}-\mathrm{OH}$ functional group. Their reactivity can proceed through two different pathways, 1-2 hydrogen shift (DeCosta and Pincock, 1989)

$>\mathrm{CH}\left(\mathrm{O}^{\circ}\right) \rightarrow>\mathrm{C}^{\circ}(\mathrm{OH})$

and C-C bond scission (Hilborn and Pincock, 1991):

$\mathrm{R}-\mathrm{CH}\left(\mathrm{O}^{\prime}\right) \mathrm{R}^{\prime} \rightarrow>\mathrm{RCH}(=\mathrm{O})+\mathrm{R}^{\prime}$

Both pathways are non-limiting steps that are in competition with each other. Schuchmann et al. (1985) studied the fate of acetate peroxyl radicals and showed that 
the produced alkoxyl radical $\left(\mathrm{CH}_{2}\left(\mathrm{O}^{*}\right) \mathrm{C}(=\mathrm{O})\left(\mathrm{O}^{-}\right)\right)$may be degraded following Reactions (R15) and (R16). However, they could not determine the relative contribution of both reaction pathways to the degradation of the alkoxyl radical. In our mechanism, bond scission (Reaction R16) is the only possible reaction when a neighboring carbon atom is oxygenated. The scission leads to the formation of the most stable radicals; i.e., the formation of secondary radicals is favored over the formation of primary radicals. Alkoxyl radicals evolve through a 1-2 hydrogen shift (Reaction R15) when the neighboring carbon atoms are not oxygenated.

Because of their very short lifetimes, alkoxyl radicals are not explicitly considered in the mechanism. Instead, electron transfer and fragmentation products are directly included in the global reaction. For example, for the $\beta$ hydroxyethylperoxyl radical using the rate constant and branching ratios from Piesiak et al. (1984) (see Reaction R9),

\begin{tabular}{|c|c|c|}
\hline $\begin{array}{l}\text { Pathway 1: } \\
2 \mathrm{CH}_{2}(\mathrm{OH}) \mathrm{CH}_{2}(\mathrm{OO}) \rightarrow \\
2 \mathrm{CHOCH}_{2}(\mathrm{OH})+\mathrm{H}_{2} \mathrm{O}_{2}\end{array}$ & $\begin{aligned} k= & 5.0 \times 10^{7} \\
& \mathrm{M}^{-1} \mathrm{~s}^{-1}\end{aligned}$ & $\begin{array}{l}\text { Piezak et al. } \\
\text { (1984) }\end{array}$ \\
\hline $\begin{array}{l}\text { Pathway 2: } \\
2 \mathrm{CH}_{2}(\mathrm{OH}) \mathrm{CH}_{2}\left(\mathrm{OO}^{\prime}\right) \rightarrow \\
\mathrm{CHOCH}_{2}(\mathrm{OH}) \\
+\mathrm{CH}_{2}(\mathrm{OH}) \mathrm{CH}_{2}(\mathrm{OH})+\mathrm{O}_{2}\end{array}$ & $\begin{aligned} k= & 3.3 \times 10^{7} \\
& \mathrm{M}^{-1} \mathrm{~s}^{-1}\end{aligned}$ & $\begin{array}{l}\text { Piezak et al. } \\
\text { (1984) }\end{array}$ \\
\hline $\begin{array}{l}\text { Pathway 3: } \\
2 \mathrm{CH}_{2}(\mathrm{OH}) \mathrm{CH}_{2}\left(\mathrm{OO}^{\prime}\right) \rightarrow \\
2 \mathrm{CH}_{2}\left(\mathrm{O}^{\cdot}\right) \mathrm{CH}_{2}(\mathrm{OH})+\mathrm{O}_{2} \\
\mathrm{CH}_{2}\left(\mathrm{O}^{\cdot}\right) \mathrm{CH}_{2}(\mathrm{OH}) \rightarrow \\
\mathrm{C}^{\cdot} \mathrm{H}_{2}(\mathrm{OH})+\mathrm{CH}_{2} \mathrm{O} \\
\mathrm{C}^{\cdot} \mathrm{H}_{2}(\mathrm{OH})+\mathrm{O}_{2} \rightarrow \\
\mathrm{CH}_{2}(\mathrm{OH})(\mathrm{OO} \cdot)\end{array}$ & $\begin{array}{l}k=1.7 \times 10^{7} \\
\quad \mathrm{M}^{-1} \mathrm{~s}^{-1} \\
\text { Fast } \\
k=2.0 \times 10^{9} \\
\quad \mathrm{M}^{-1} \mathrm{~s}^{-1}\end{array}$ & $\begin{array}{l}\text { Piezak et al. } \\
\text { (1984) }\end{array}$ \\
\hline $\begin{array}{l}2 \mathrm{CH}_{2}(\mathrm{OH}) \mathrm{CH}_{2}(\mathrm{OO}) \rightarrow \\
1.33 \mathrm{CHOCH}_{2}(\mathrm{OH}) \\
+0.33 \mathrm{CH}_{2}(\mathrm{OH}) \mathrm{CH}_{2}(\mathrm{OH}) \\
+0.34 \mathrm{CH}_{2} \mathrm{O} \\
+0.34 \mathrm{CH}_{2}(\mathrm{OH})(\mathrm{OO} \cdot) \\
+0.50 \mathrm{H}_{2} \mathrm{O}_{2} \\
+0.16 \mathrm{O}_{2}-0.34 \mathrm{H}_{2} \mathrm{O}\end{array}$ & $\begin{aligned} k= & 1.0 \times 10^{8} \\
& \mathrm{M}^{-1} \mathrm{~s}^{-1}\end{aligned}$ & $\begin{array}{l}\text { Piezak et al. } \\
\text { (1984) }\end{array}$ \\
\hline
\end{tabular}

The last reaction is the overall budget reaction, which is taken into account in the model.

\section{Coupling CLEPS with MCM v3.3.1 mass transfer}

\subsection{Gas phase mechanism}

The CLEPS mechanism is coupled to the gas phase Master Chemical Mechanism, MCM v3.3.1 (Jenkin et al., 2015; Saunders et al., 2003) provided at http://mcm.leeds.ac. uk/MCM. The new version 3.3.1 of MCM includes in particular the treatment of isoprene oxidation products such as epoxydiols, hydroxymethylmethyl- $\alpha$-lactone (HMML) and methacrylic acid epoxide (MAE).

All gases are dissolved in CLEPS even if they are not further oxidized in the aqueous phase. Conversely, some aqueous species described in CLEPS can be outgassed even if there is no corresponding gas species in MCM. Among the 87 chemical species included in CLEPS, 33 do not have a counterpart in MCM. These are mostly highly oxygenated and highly soluble species. Conversely, 267 gas phase species from MCM have no corresponding aqueous species in CLEPS. We made sure that all species have an equivalent in the respective other phase, even if this species in that phase is not reactive. The mass transfer parameters are estimated as described below (Sect. 4.2).

\subsection{Estimating mass transfer parameters}

Mass transfer is described following the kinetic parameterization from Schwartz (1986). For a given species A,

$\left\{\begin{array}{l}\mathrm{A}_{(\mathrm{g})} \stackrel{k_{\mathrm{I}}}{\rightarrow} \mathrm{A}_{(\mathrm{aq})}, \\ \mathrm{A}_{(\mathrm{aq})} \stackrel{k_{\mathrm{I}} / \mathrm{H}_{\mathrm{A}}}{\longrightarrow} \mathrm{A}_{(\mathrm{g})},\end{array}\right.$

where $\mathrm{H}_{\mathrm{A}}\left(\mathrm{M} \mathrm{atm}^{-1}\right)$ is the Henry's law constant for species $\mathrm{A}$ and $k_{\mathrm{I}}$ is the pseudo first-order rate constant for mass transfer:

$k_{\mathrm{I}}=L k_{\mathrm{T}}=L\left(\frac{r^{2}}{3 D_{\mathrm{g}}}+\frac{4 r}{3 v \alpha}\right)^{-1}$,

where $L$ (vol. water/vol. air) is the liquid water content of the cloud, $r(\mathrm{~cm})$ is the radius of the droplets, $D_{\mathrm{g}}$ $\left(\mathrm{cm}^{2} \mathrm{~s}^{-1}\right)$ is the gas diffusion coefficient, $v\left(\mathrm{~cm} \mathrm{~s}^{-1}\right)$ is the mean molecular speed and $\alpha$ (dimensionless) is the mass accommodation coefficient. The parameters $\mathrm{H}_{\mathrm{A}}, D_{\mathrm{g}}, v$, and $\alpha$ are documented for each soluble species in order to fully describe mass transfer. Estimates of unknown parameters are obtained following the approach of Mouchel-Vallon et al. (2013). The Henry's law coefficients are provided by the GROMHE SAR (Raventos-Duran et al., 2010). Comparing this SAR with other available methods (Meylan and Howard, 2000; Hilal et al., 2008), Raventos-Duran et al. (2010) have shown that GROMHE is the more reliable SAR in general, estimating Henry's law constants with a root mean square error of $0.38 \mathrm{log}$ units (approx. a factor of 2). It particularly shows better performances than the other tested methods for the more soluble species, i.e. highly oxygenated, multifunctional organic species.

When unavailable, the temperature dependencies (enthalpy of dissolution) are set to $50 \mathrm{~kJ} \mathrm{~mol}^{-1} \cdot D_{\mathrm{g}}$ is calculated by scaling from a reference compound $\left(\frac{D_{\mathrm{g}, \mathrm{A}}}{D_{\mathrm{g}, \mathrm{H}_{2} \mathrm{O}}}=\sqrt{\frac{M_{\mathrm{H}_{2} \mathrm{O}}}{M_{\mathrm{A}}}}, \quad\right.$ where $\quad D_{\mathrm{g}, \mathrm{H}_{2} \mathrm{O}}=0.214 / P \mathrm{~cm}^{2} \mathrm{~s}^{-1}$, $P(\mathrm{~atm})$ is the atmospheric pressure and $M_{\mathrm{A}}$ is the molar mass $\left(\mathrm{g} \mathrm{mol}^{-1}\right)$; Ivanov et al., 2007). 


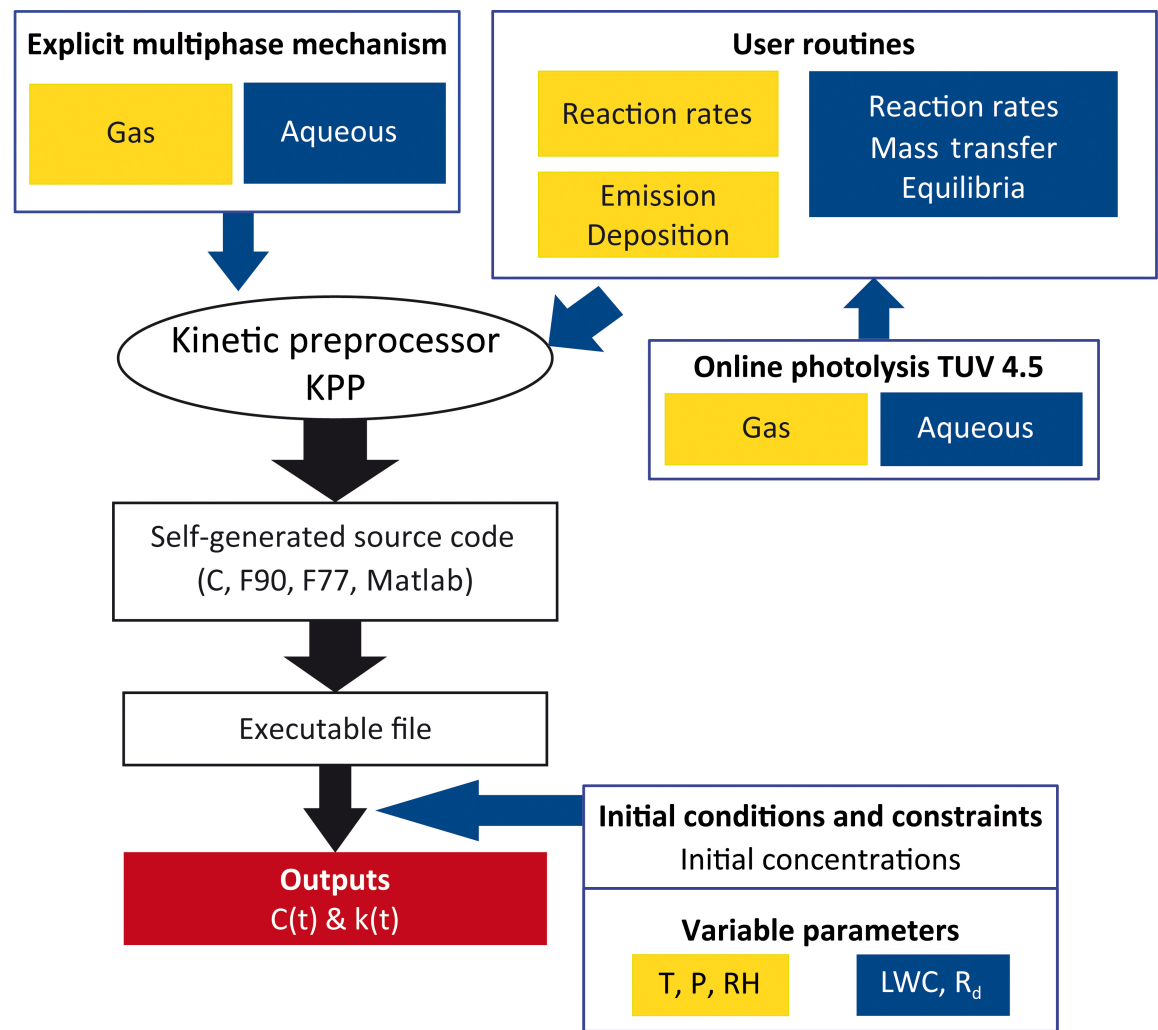

Figure 2. Schematic diagram of the DSMACC version of the Kinetic PreProcessor. The developments related to aqueous phase reactivity are shown in blue.

The mean molecular speed is defined as $\sqrt{\frac{8 R^{\prime} T}{\pi M_{\mathrm{A}}}}$ with $\quad R^{\prime}=8.3145 \times 10^{7} \mathrm{~g} \mathrm{~cm}^{2} \mathrm{~s}^{-2} \mathrm{~K}^{-1} \mathrm{~mol}^{-1}$. The accommodation coefficients are set to a default value of $\alpha=0.05$ when no data are available (Lelieveld and Crutzen, 1991; Davidovits et al., 2006, 2011). We add the temperature dependence of the mass accommodation coefficients based on the parameterization from Nathanson et al. (1996):

$\frac{\alpha}{1-\alpha}=e^{-\frac{\Delta G_{\mathrm{obs}}}{R T}}$

$\Delta G_{\mathrm{obs}}=\Delta H_{\mathrm{obs}}-T \Delta S_{\mathrm{obs}}\left(\mathrm{J} \mathrm{mol}^{-1}\right)$ is interpreted as the free energy, where $\Delta H_{\mathrm{obs}}\left(\mathrm{J} \mathrm{mol}^{-1}\right)$ and $\Delta S_{\mathrm{obs}}\left(\mathrm{J} \mathrm{mol}^{-1} \mathrm{~K}^{-1}\right)$ are thermodynamic solvation parameters (free enthalpy and entropy) derived by Nathanson et al. (1996) from experimental works on the heterogeneous uptake coefficients performed at different temperatures. When $\Delta H_{\mathrm{obs}}$ and $\Delta S_{\mathrm{obs}}$ are experimentally available, they are used to estimate the temperature-dependent $\alpha$, and in other cases, if the value of $\alpha$ is available in the literature, it is used without the temperature dependency.

The mass transfer parameterization in our cloud chemistry model has been used for a long time (Jacob, 1986). Most cloud chemistry models use experimentally measured Henry's law constants. Ervens et al. (2003) proposed estimating the accommodation coefficient based on using a SAR to empirically estimate $\Delta G_{\text {obs }}$. As underlined by Ervens et al. (2003), this method should be used very carefully because the data needed to validate this method are very scarce. Future works could focus on (i) the sensitivity of the system to $\alpha$ estimates and (ii) refining the SAR according to the more recent data reported in Davidovits et al. (2011).

\subsection{Model description}

The mechanism resulting from the coupling of CLEPS with MCM v3.3.1 is integrated into a model based on the Dynamically Simple Model for Atmospheric Chemical Complexity (DSMACC; Emmerson and Evans, 2009) using the Kinetic PreProcessor (KPP: see Damian et al., 2002), which has been modified to account for an aqueous phase, as described in the following. The changes are summarized in blue in Fig. 2.

Aqueous phase reactions are implemented as a new reaction type. Rate constants in units of $\mathrm{M}^{-n} \mathrm{~s}^{-1}$ are converted to $\operatorname{molec}^{-n} \mathrm{~cm}^{-3 n} \mathrm{~s}^{-1}$, depending on the constrained liquid water content. Aqueous phase equilibria are decomposed as forward and backward reactions. This alternative to the total species approach used in other models (Leriche et al., 2000) has the drawback of making the ODE (ordinary differential equation) system stiffer. However, 
in our simulation, the model handles the stiffness without noticeable numerical issues. Moreover, this approach has the advantage of allowing the explicit treatment of crossequilibria. The $\mathrm{pH}$ therefore evolves dynamically as $\mathrm{H}^{+}$ is explicitly produced and consumed in the equilibrium reactions.

Mass transfer is also implemented as a new reaction type. The mass transfer coefficients are calculated following Schwartz (1986) and depend on the Henry's law constants, gas diffusion coefficients, mean molecular speeds and accommodation coefficients (see Sect. 4.2).

The TUV version (TUV 4.5, Emmerson and Evans, 2009) included in DSMACC to calculate the photolysis rates in the gas phase has been modified to include aqueous phase photolysis reactions (Fig. 2). To calculate the photolysis coefficients inside the droplets, the clear-sky actinic flux values are multiplied by a factor of 1.6 (Ruggaber et al., 1997), and the cross sections and quantum yields are provided from available experimental data (Deguillaume et al., 2004; Long et al., 2013).

Differential equations are solved with a Rosenbrock solver, which has been shown to be a reliable numerical method for stiff ODE systems involved in modeling multiphase chemistry (Djouad et al., 2002, 2003).

\section{Comparison with existing cloud aqueous phase mechanisms}

The Cloud Explicit Physicochemical Scheme (CLEPS 1.0) has been developed in the most explicit way to take into account the most probable oxidation pathways of organic compounds. The protocol that is applied to develop CLEPS is in the same spirit as CAPRAM 3.0 (Chemical Aqueous Phase Radical Mechanism; Herrmann et al., 2005; Tilgner and Herrmann, 2010; Whalley et al., 2015). In this section, it is important to compare the main stages of the building of both aqueous phase mechanisms (CLEPS vs. CAPRAM).

CLEPS and CAPRAM present similarities. They are both developed on the hypothesis in the choice of chemical pathways and rate constants that are carefully calibrated against experimental data when available. For instance, inorganic chemistry, acidity constant estimates, and photolysis rate calculations are similar in both aqueous mechanisms. These two mechanisms were built upon their own set of recommended data (e.g., Ervens et al., 2004, for CAPRAM; Leriche et al., 2000, 2003, 2007; Deguillaume et al., 2004, for CLEPS). However, some differences exist and are listed below. Those differences are justified with the way both mechanisms will be applied for coupling with a regional/global model, interpreting laboratory and/or observational data from field experiments, introducing biodegradation processes, etc.

First of all, the two mechanisms are coupled to two quite contrasted gas phase mechanisms since CAPRAM is based upon RACM and CLEPS upon MCM. The fact that RACM (Stockwell et al., 1997) includes lumped species while MCM is fully explicit leads to different developments in the aqueous phase. In CAPRAM, the lumped gaseous species are split into several fractions that are then transferred to the corresponding species in the aqueous phase, whereas in CLEPS, individual gas species are directly transferred to the corresponding aqueous phase species. As an example, the "Ald" model species in RACM represents all gaseous aldehydes and is considered to be the source of dissolved acetaldehyde, propionaldehyde and butyraldehyde (Herrmann et al., 2005).

Secondly, CAPRAM only represents one oxidation pathway for each non-radical aqueous species when, usually, in the laboratory, several first-generation oxidation products are detected (Perri et al., 2009). In CLEPS however, the various possible oxidation pathways of organic compounds are considered. In this regard, CLEPS is more likely to take into account the variety of oxidation products. For instance, in Table 2 the hydrated glycolaldehyde final reactivity in CLEPS is equally distributed between three $\mathrm{HO}^{\circ}$ attack sites and yields $33 \%$ glyoxylic acid, $28 \%$ glyoxal, $39 \%$ formic acid and formaldehyde. This result can be compared with the mechanism in CAPRAM 2.4 (Ervens et al., 2004) which leads to $100 \%$ glyoxylic acid since it only considers the aldehydic hydrogen abstraction.

Then, an important difference between CLEPS and CAPRAM lies in the hypotheses that are made when rate constants, branching ratios, solubility and hydration constants are missing. In CLEPS, the recent SAR from Doussin and Monod (2013) is systematically applied to estimate rate constants and branching ratios for the $\mathrm{HO}$. oxidation. In CAPRAM, Herrmann et al. (2005) and Tilgner et al. (2013) may rely on similarities when data are not available: for instance, they assume that the $\mathrm{HO}^{-}$addition rate constant on 2,3-dihydroxy-4-oxobutanoic acid is the same as maleic acid. In most cases, they assume that the reaction will proceed through the identified most probable pathway using the bond dissociation energy measurements (BDEs) (Benson, 1976; Evans and Polanyi, 1938). In some other cases, like for 2,4-butanedione, they attribute branching ratios from the equivalent measured gas phase reaction.

There is one exception for the estimation of $\mathrm{NO}_{3}$ reaction rates since no SARs have been available up to now. In CLEPS, similarity criteria are used for the rate constants and branching ratios are estimated in the same way as for $\mathrm{HO}$. In CAPRAM, Evans-Polanyi-type correlations are used to estimate the rate constants assuming that the $\mathrm{H}$-abstraction only occurs at the weakest $\mathrm{C}-\mathrm{H}$ bond (Herrmann and Zellner, 1998; Hoffmann et al., 2009).

In CLEPS, even solubility and hydration constants are estimated using SAR (GROMHE). In this way, all species identified in gas phase mechanism MCM are dissolved in CLEPS, whereas in CAPRAM only some organic compounds are transferred in the aqueous phase when their 
solubility is documented or estimated based on similarity criteria.

Some attention should be paid when comparing the hypotheses made to develop CLEPS and CAPRAM since some of them are related to deliquescent particles and/or cloud droplets. CAPRAM, in contrast to CLEPS, explicitly treats the $\mathrm{O}_{2}$-addition step on the alkyl radicals. This allows the direct treatment of the alkyl+alkyl vs. alkyl $+\mathrm{O}_{2}$ competition that may occur in deliquescent particles. In CLEPS, the fate of peroxyl radicals is an attempt at systematizing the approach used in CAPRAM that also considers peroxyl radical recombination reactions using experimental data from Zegota et al. (1986), Schuchmann et al. (1985) and Poulain et al. (2010). The possible crossreactions are not considered in either of these aqueous phase mechanisms.

To summarize, CLEPS is based upon one of the most updated gas chemical mechanisms (MCM) that uses the very efficient preprocessor KPP and Rosenbrock solver. This is a good basis to develop an explicit aqueous phase chemistry model that is suitable for interpreting laboratory data and for describing the phase separation observed in long-term measurement stations (from the WMO and/or ACTRIS networks).

\section{Simulation of a test case}

\subsection{Initial conditions}

The model is run with the initial and environmental conditions adapted from the low- $\mathrm{NO}_{x}$ situation described by McNeill et al. (2012). Information about the emissions, deposition and initial concentrations of chemical species is provided in Table 4. The situation corresponds to summertime conditions, with the simulation starting on 21 June $(1000 \mathrm{hPa}, 290.15 \mathrm{~K}, 10 \%$ relative humidity). The coordinates used to calculate actinic fluxes are $45.77^{\circ} \mathrm{N}$, $2.96^{\circ} \mathrm{E}$. The main difference with the situation described in McNeill et al. (2012) is that isoprene is the only emitted primary organic compound. To compensate for the decrease in total emitted organic mass, the isoprene emission is increased from $1.5 \times 10^{6}$ in McNeill et al. (2012) to $7.5 \times 10^{6} \mathrm{molec} \mathrm{cm}^{-3} \mathrm{~s}^{-1}$ in our work. Furthermore, dry deposition is added for the major oxidation products of isoprene to prevent the accumulation of secondary organic species. The temperature is held constant $(290.15 \mathrm{~K})$ during the whole simulation. Under these chemical conditions, the gas chemistry simulation has been run for 31 days (see Supplement SM3).

At noon on the 31st day of the simulation, relative humidity is increased to $100 \%$ and aqueous phase conditions are activated assuming a constant liquid water content of $3 \times 10^{-7}$ vol. water/vol. air with a fixed droplet radius of $10 \mu \mathrm{m}$ for $12 \mathrm{~h}$. As a first attempt, the cloud is supposed to be permanent in order to check that the mechanism is (i) working as intended and (ii) producing chemical effects in both phases. Testing the model over $12 \mathrm{~h}$ is a first step to evaluate the impacts (or their absence) of detailed organic chemistry on multiphase cloud chemistry. Future studies will use variable environmental conditions that require the consideration of microphysical processes with our multiphase chemical module.

The cloud scenario is initialized with $1 \mu \mathrm{M}$ of iron, which is a typical concentration in continental cloud water (Deguillaume et al., 2014), to enable recycling of oxidants by redox cycles involving iron. The initial $\mathrm{pH}$ is set to 4 and is free to evolve. The $\mathrm{pH}$ quickly reaches 3.2 (see Supplement SM4). An additional simulation is performed to consider the aqueous reactivity of dissolved organic species from the gas phase mechanism, the reactivity of which is not represented in our aqueous phase mechanism. Each of these dissolved organic species reacts with the $\mathrm{HO}^{\circ}$ radicals with a rate constant of $k=3.8 \times 10^{8} \mathrm{M}^{-1} \mathrm{~s}^{-1}$. This value is taken from the work of Arakaki et al. (2013), which estimated the sink for aqueous $\mathrm{HO}$ by dissolved organic carbon (DOC). This additional sensitivity test (called "with DOC") is performed to improve the estimate of the $\mathrm{HO}$ concentrations in the atmospheric drops. To account for the conversion of radicals, we assume that each of these reactions produces an $\mathrm{HO}_{2}$ radical in the aqueous phase.

\subsection{Gas chemical reactivity}

Figure $3 \mathrm{a}$ and $\mathrm{b}$ show the time evolution of the targeted gases during the 31 st day of the gas phase simulation (dashed lines). The $\mathrm{NO}_{x}$ and $\mathrm{O}_{3}$ mixing ratios (Fig. 3a) are 0.54 and 87 ppbv, respectively, at noon, while the $\mathrm{HO}^{\circ}$ mixing ratio reaches a maximum of $0.12 \mathrm{pptv}$. The simulated mixing ratio of isoprene (Fig. 3b) exhibits a 1.5 ppbv peak in the morning and a minimum of $0.9 \mathrm{ppbv}$ in the afternoon. Because the simulated emission of isoprene is constant during the day (and is turned off at night), its time evolution is constrained by the daytime evolution of its oxidants $\mathrm{HO}^{\circ}$ and $\mathrm{O}_{3}$. In this case, the $\mathrm{HO}$ radical is the main oxidant of isoprene $\left(k_{\mathrm{HO}+\text { isoprene }} \times C_{\mathrm{HO}} \approx 10 \times k_{\mathrm{O}_{3}+\text { isoprene }} \times C_{\mathrm{O}_{3}}\right)$. Therefore, simulated isoprene exhibits a minimum at noon, when $\mathrm{HO}$ reaches its maximum. The resulting isoprene diurnal profile is not realistic, as in the atmosphere the isoprene diurnal profile is constrained by the diurnal variation of both its emissions and level of oxidants. The oxidation of isoprene leads to the production of secondary organic species. The time evolutions of the most important secondary species are depicted in Fig. 3b. The first oxidation products from isoprene (MACR, MVK) follow the same time profile as isoprene. The mixing ratios of other oxidation products vary also temporally depending on their production/destruction rates. For example, MGLY, GLY and glycolaldehyde mixing ratios decrease initially due to their oxidation by $\mathrm{HO}$ 
Table 4. (a) Chemical scenario used for the gas phase simulation of 31 days. (b) Aqueous phase initial concentration.

\begin{tabular}{|c|c|c|c|c|}
\hline (a) & Gas phase species & $\begin{array}{r}\text { Initial mixing } \\
\text { ratio (ppb) }\end{array}$ & $\begin{array}{r}\text { Emission } \\
\left(\text { molec } \mathrm{cm}^{-3} \mathrm{~s}^{-1}\right)\end{array}$ & $\begin{array}{r}\text { Deposition } \\
\left(\mathrm{s}^{-1}\right)\end{array}$ \\
\hline & $\mathrm{SO}_{2}$ & 1 & $2.91 \times 10^{5}$ & $1 \times 10^{-5}$ \\
\hline & NO & - & $2.86 \times 10^{5}$ & 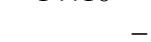 \\
\hline & $\mathrm{NO}_{2}$ & 0.3 & - & $4 \times 10^{-6}$ \\
\hline & $\mathrm{N}_{2} \mathrm{O}_{5}$ & - & - & $2 \times 10^{-5}$ \\
\hline & $\mathrm{HNO}_{3}$ & 0.3 & - & $2 \times 10^{-5}$ \\
\hline & $\mathrm{O}_{3}$ & 40 & - & $4 \times 10^{-6}$ \\
\hline & $\mathrm{H}_{2} \mathrm{O}_{2}$ & 1 & - & $1 \times 10^{-4}$ \\
\hline & $\mathrm{CH}_{4}$ & $1.7 \times 10^{3}$ & _ & - \\
\hline & $\mathrm{CO}_{2}$ & $3.57 \times 10^{5}$ & - & - \\
\hline & $\mathrm{CO}$ & $1.5 \times 10^{2}$ & $3.7 \times 10^{6}$ & $1 \times 10^{-6}$ \\
\hline & Isoprene & 1 & $7.50 \times 10^{6 *}$ & - \\
\hline & Dihydroxybutanone & - & - & $5 \times 10^{-5}$ \\
\hline & MACR & - & - & $5 \times 10^{-5}$ \\
\hline & MVK & - & - & $5 \times 10^{-5}$ \\
\hline & Glyoxal & 0.1 & - & $5 \times 10^{-5}$ \\
\hline & Methylglyoxal & 0.1 & - & $5 \times 10^{-5}$ \\
\hline & Glycolaldehyde & - & - & $5 \times 10^{-5}$ \\
\hline & Acetaldehyde & 0.1 & $3.17 \times 10^{3}$ & $5 \times 10^{-5}$ \\
\hline & Formaldehyde & 0.5 & $3.03 \times 10^{3}$ & $5 \times 10^{-5}$ \\
\hline & Acetone & 0.1 & $8.92 \times 10^{3}$ & $5 \times 10^{-5}$ \\
\hline & Pyruvic acid & - & - & $5 \times 10^{-5}$ \\
\hline & Acetic acid & $1 \times 10^{-3}$ & $3.35 \times 10^{3}$ & $5 \times 10^{-5}$ \\
\hline & Formic acid & - & - & $5 \times 10^{-5}$ \\
\hline & Methanol & 2 & $1.07 \times 10^{4}$ & $5 \times 10^{-5}$ \\
\hline & Methylhydroperoxide & 0.01 & $3.35 \times 10^{3}$ & $5 \times 10^{-6}$ \\
\hline (b) & Aqueous phase species & $\begin{array}{r}\text { Initial concentration } \\
(\mu \mathrm{M})\end{array}$ & & \\
\hline & $\mathrm{Fe}^{2+}$ & 1 & & \\
\hline
\end{tabular}

* 0 at night-time concentration; see text.

and then increase strongly due to their production by the oxidation of isoprene.

\subsection{Impact of aqueous phase reactivity}

Figure $3 \mathrm{a}$ and $\mathrm{b}$ show the time evolution of targeted gases during the cloud scenario (full lines) compared to the gas phase scenario (dashed lines). Previous modeling studies have shown that gas phase $\mathrm{HO}_{x}$ chemistry is modified by the aqueous $\mathrm{HO}_{2}$ chemistry (Jacob, 1986; Monod and Carlier, 1999). Recent experimental results from Whalley et al. (2015) confirmed that uptake and reactivity in clouds can have a significant impact on the $\mathrm{HO}_{2}$ and $\mathrm{HO}^{\prime}$ concentrations in the gas phase. In the simulation, at the onset of the cloud, the $\mathrm{HO}_{2}$ mixing ratio is reduced by $17 \%$, and the HO mixing ratios increase by $75 \%$. After an initial sharp decrease, the $\mathrm{H}_{2} \mathrm{O}_{2}$ mixing ratio exhibits a $50 \%$ increase after $4 \mathrm{~h}$ compared to the cloud-free situation. The increase in the $\mathrm{HO}^{\circ}$ mixing ratios is caused by the important dissolution of organic matter, leading to reduced $\mathrm{HO}^{\circ}$ sinks in the gas phase. $\mathrm{H}_{2} \mathrm{O}_{2}$ is a soluble species highly reactive with $\mathrm{SO}_{2}$, which explains the initial dip in its mixing ratio. After $\mathrm{SO}_{2}$ is entirely depleted (not shown), the aqueous production of $\mathrm{H}_{2} \mathrm{O}_{2}$ is responsible for its subsequent higher gaseous levels.

This trend in $\mathrm{HO}$ mixing ratios contradicts previous modeling results (Herrmann et al., 2000; Barth et al., 2003; Ervens et al., 2003; Tilgner et al., 2013) which exhibit a decrease in $\mathrm{HO}$ mixing ratios during cloud events. The chosen chemical scenario might be the reason for this difference. In our test simulations, isoprene is the main emitted organic compound with a small contribution of formaldehyde and acetaldehyde, whereas a larger range of hydrocarbons of anthropogenic (alkanes, alkenes, aromatics) and biogenic origin (limonene, $\alpha$-pinene) are emitted in Ervens et al. (2003). In the CAPRAM model setup, these hydrocarbons are not dissolved, and it should be noted that they are highly reactive with $\mathrm{HO}$. This means that the 

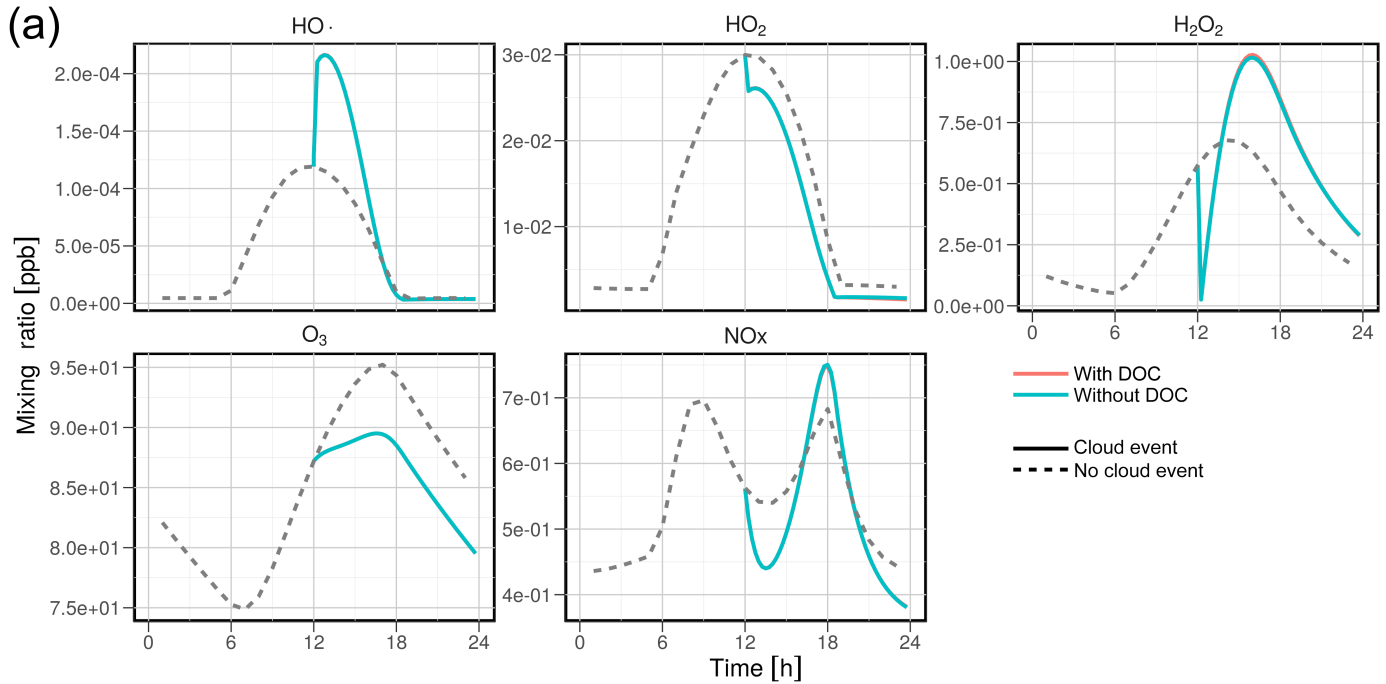

(b)
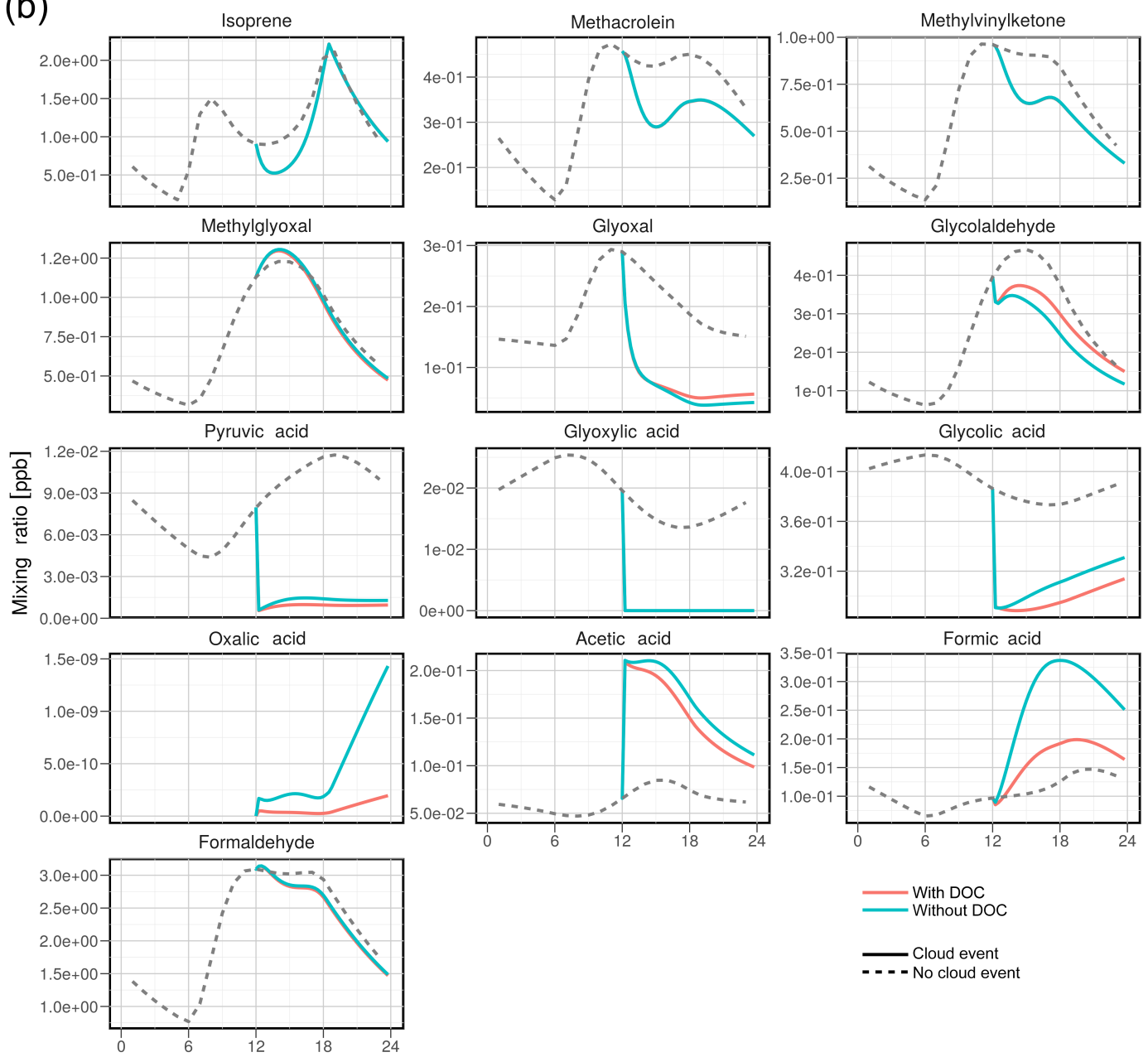

Time $[\mathrm{h}]$

Figure 3. Time evolution of the gas phase mixing ratios without the cloud (dashed lines) and during the cloud (continuous line). The cloud simulations are depicted with (red lines) and without (blue lines) DOC. Please note that for most plots, the red line is hidden by the blue line. 
large, and certainly major, sink of gaseous $\mathrm{HO}^{\circ}$ caused by hydrocarbon reactivity is always present, even under cloudy conditions. When the source of $\mathrm{HO}^{-}$radicals is reduced by the cloud (e.g. due to $\mathrm{HO}_{2}$ and $\mathrm{NO}$ separation), $\mathrm{HO}$ radical sinks are not significantly perturbed and $\mathrm{HO}^{\prime}$ steady-state mixing ratios decrease. Conversely, in our simulation the gaseous $\mathrm{HO}$ sink is more significantly perturbed by the cloud because most of the organic matter in our scenario is produced from isoprene oxidation and is readily soluble. In our case, it seems that the HO gaseous source reduction is overcompensated by the reduction in $\mathrm{HO}^{\prime}$ gaseous sinks. As a consequence, $\mathrm{HO}^{*}$ steady-state mixing ratios are higher during cloud events. This hypothesis especially highlights how the chosen chemical scenario and regime are important for simulation results and conclusions. Future work should therefore systematically explore cloud simulations under a large range of scenarios.

Glyoxal, glycolaldehyde, pyruvic acid, glyoxylic acid and glycolic acid are readily soluble species that react in the aqueous phase (Herrmann et al., 2015), explaining the sharp decrease in their gas phase mixing ratios. Cloud dissolution and oxidation act as significant sinks for these species. For instance, the glyoxal mixing ratio is reduced by $67 \%$ at the start of the cloud, and the glycolaldehyde mixing ratio is significantly reduced until sunset (18:45). For all secondary organic species, daytime gas phase oxidation is increased due to the higher $\mathrm{HO}^{\circ}$ mixing ratios. However, the aqueous phase is also a source of secondary organic species. For species that are universal intermediates or end products, the aqueous phase production can be outgassed and contribute to maintaining cloud-free conditions' mixing ratios (methylglyoxal, formaldehyde) or significantly increase the mixing ratios compared to cloud-free conditions (acetic and formic acids). Aqueous phase production is also responsible for introducing an infinitesimal amount of oxalic acid $\left(<10^{-9} \mathrm{ppbv}\right)$ into the gas phase, as there is no oxalic acid formation pathway in the gas phase. The addition of the missing aqueous HO sink due to reaction with all dissolved unreactive species (red lines in Fig. 3a and b) leads to higher concentrations of species for which reactive uptake is an overall sink (e.g., glyoxal, glycolaldehyde). In this additional HO sink, the reduced aqueous HO concentrations (see Fig. 4) limit the impact of the aqueous sink. In contrast, lower aqueous HO concentrations reduce the gas phase mixing ratios of species for which the aqueous phase reactivity is an important source (e.g., formic, acetic and glycolic acids).

Figure 4 shows the time evolution of the main organic aqueous species together with the $\mathrm{H}_{x} \mathrm{O}_{y}$ compounds during the cloud scenario. The dissolved $\mathrm{HO}^{\circ}$ concentration reaches a peak at $8.5 \times 10^{-14} \mathrm{M}$, which is similar to the dissolved HO concentrations simulated by Tilgner et al. (2013) for non-permanent clouds in remote conditions and compiled by Arakaki et al. (2013). The oxalic acid concentration is low during the day (approximately $2 \times 10^{-8} \mathrm{M}$ ) because it is present in the form of iron-oxalate complexes, which are readily photolyzed. Therefore, during the night (from 18:45 to 00:00), the oxalic acid concentration increases significantly to $10^{-7} \mathrm{M}$.

The sensitivity test including the additional DOC sink shows that the reduced concentration of $\mathrm{HO}$ radicals (from 8.5 to $3.0 \times 10^{-14} \mathrm{M}$ maximum concentration) decreases the sinks of aqueous species from the gas phase (glycolaldehyde, methylglyoxal and 3,4-dihydroxybutanone), leading to higher aqueous phase concentrations. Conversely, the organic species, which are mostly produced in the aqueous phase (formic, pyruvic, glyoxylic, and oxalic acid) have reduced sources and sinks when $\mathrm{HO}^{\circ}$ radicals are scavenged by the added DOC. Their chemistry is slowed down and their rates of production are slower, giving lower maximum concentrations. MACR and MVK are also less sensitive to the DOC addition. Their main source in water is their mass transfer after gas phase production. This is consistent with their behavior in the gas phase during the cloud event and could explain why they are less sensitive to the HO concentrations.

A detailed budget of aqueous $\mathrm{HO}$ sinks and sources during the cloud period for the simulation with added DOC (see Supplement SM5) shows that $\mathrm{H}_{2} \mathrm{O}_{2}$ is the main source of $\mathrm{HO}^{\circ}$ via the Fenton reaction and its photolysis. However, in the first hours of the cloud, mass transfer is the major source of $\mathrm{HO}$, as was predicted in a previous modeling study on a shorter cloud event considering a remote chemical scenario (Tilgner et al., 2013). Fenton-type reactions and photolysis reaction are also significant sources of $\mathrm{HO}^{\circ}$ in their simulation. Organics are the most important $\mathrm{HO}$ sinks, with DOC contributing $64 \%, \mathrm{C}_{2}$ compounds contributing $18 \%$, and $\mathrm{C}_{4}$ compounds contributing $12 \%$ of $\mathrm{HO}$ destruction. $\mathrm{C}_{1}$ and $\mathrm{C}_{3}$ together are responsible for $5 \%$ of the HO sink. Tilgner et al. (2013) also show that $\mathrm{HO}^{-}$-only aqueous sinks are reactions with organic matter, especially carbonyl compounds such as hydrated formaldehyde, glycolaldehyde and methylglyoxal.

Figure 5 depicts the contributions in terms of concentrations of the major species in the aqueous phase. The total concentration of organic matter (continuous line) reaches a maximum of $0.76 \mathrm{mM}$ after $12 \mathrm{~h}$ of cloud simulation, which corresponds to approximately $30 \mathrm{mCL} \mathrm{L}^{-1}$. This value is high but on the order of magnitude of the DOC measurements (Deguillaume et al., 2014; Giulianelli et al., 2014; Herckes et al., 2013, 2015; van Pinxteren et al., 2016). However, species whose reactivity is represented in the CLEPS aqueous mechanism (dashed line in Fig. 5) constitute only $16 \%$ of the total concentration of dissolved species. Not all species dissolved from the MCM undergo a reactive sink reaction in the aqueous phase (see the list in Supplement SM6). The 10 most abundant species in the aqueous phase contribute $91 \%$ of the concentration of reactive species (126 vs. $138 \mu \mathrm{M})$ and $15 \%$ of the dissolved species. Among these 


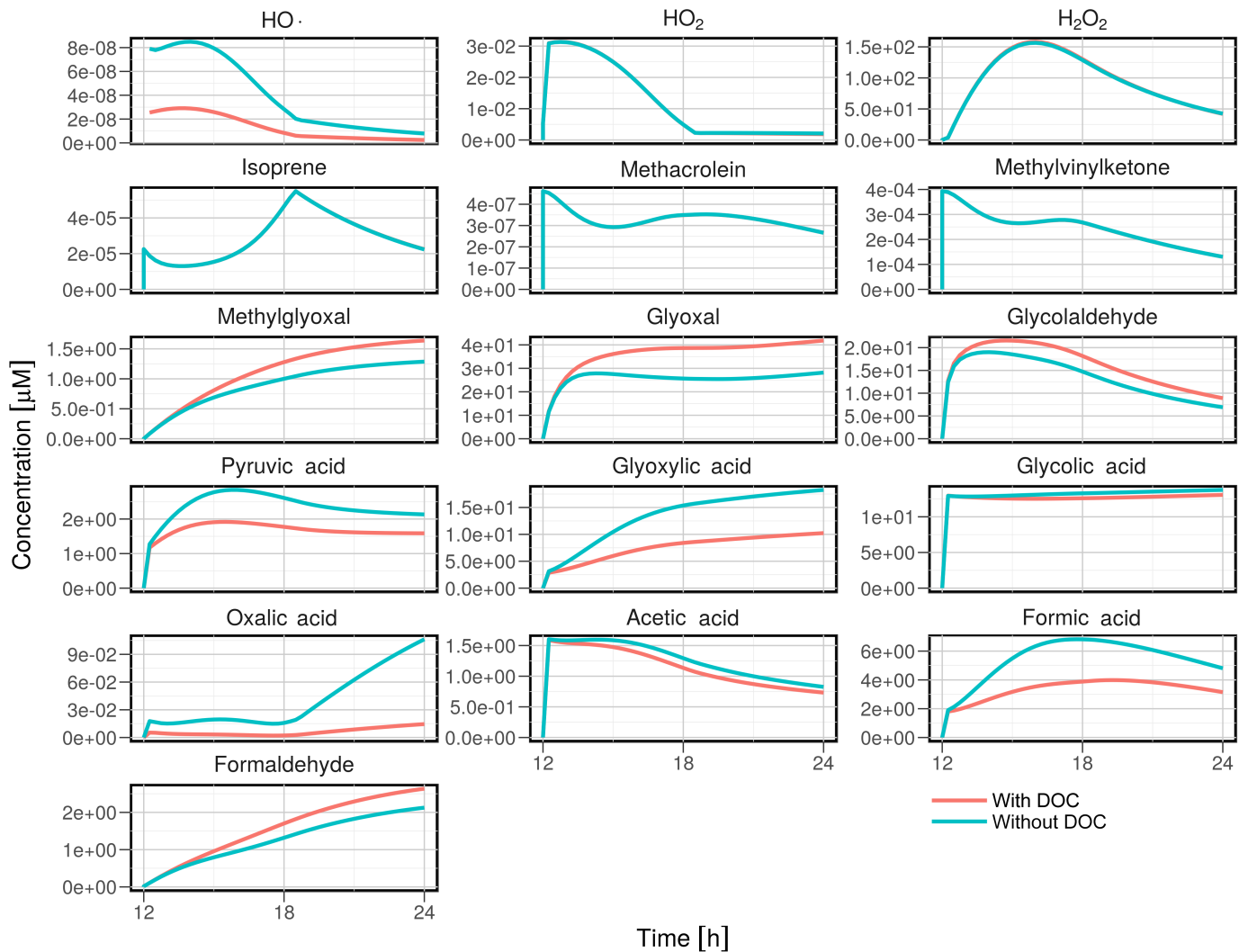

Figure 4. Time evolution of the dissolved species concentrations during the simulated cloud with (red lines) and without (blue lines) DOC. The vertical scale is in $\mu \mathrm{M}$; therefore, the HO radical concentrations are in the $10^{-14} \mathrm{M}$ range. Please note that for some plots, the red line is hidden by the blue line.

10 species, glyoxal, hydroxybutanedione, glycoladehyde, 3,4-dihydroxybutanone and glyoxylic and glycolic acids are the most important contributors. A detailed time-resolved flux analysis of the sources and sinks of these species shows that their initial concentration increase is the result of their mass transfer from the gas phase. Then, the balance between aqueous sources and sinks defines the time evolution of their concentrations. For instance, the glyoxal concentration continues increasing because of the important source of the aqueous oxidation of glycolaldehyde. The main sink of glycolaldehyde through reaction with $\mathrm{HO}^{\circ}$ is strong enough to make its concentration decrease over time. The two most important acids, glycolic and glyoxylic acids, have initial contributions from gas phase mass transfer and are then produced in the aqueous phase from the oxidation of glyoxal and glycolaldehyde. In the first hours of the simulation, acetic and formic acids' simulated concentrations are in the range of in situ measurements (Deguillaume et al., 2014). Glycolic and glyoxylic acids present high concentrations in comparison to in situ measurements, which should indicate that sources or sinks are therefore likely to be misrepresented in our mechanism.

The presence of acids as main contributors to the aqueous phase organic composition shows the potential for cloud reactivity to be a source of acids (Chameides, 1984). The total amount of organic acids (including formic and acetic acids) in both phases is almost doubled in less than $1 \mathrm{~h}$ by the aqueous phase sources, from approximately $0.48 \mathrm{ppbv}$ of gaseous organic acids before the cloud to a total of $0.98 \mathrm{ppbv}$ of organic acids in both phases (see Supplement SM7).

Figure 6 depicts the time evolution of the $\mathrm{O} / \mathrm{C}$ ratio and the mean number of carbon atoms $\left(n_{C}\right)$ in the reactive organic compounds present in the aqueous phase (excluding $\mathrm{CO}_{2}$ and iron-organic complexes) and in the gas phase (excluding $\mathrm{CO}$ and $\mathrm{CH}_{4}$ ), with and without the cloud. $\mathrm{O} / \mathrm{C}$ is the ratio between the number of organic oxygen atoms and the organic carbon atoms in gas and cloud phases. The $\mathrm{O} / \mathrm{C}$ ratios and $n_{C}$ are a measure of the extent to which long-chain organic species are oxidized and are therefore indicators of their functionalization and/or fragmentation. One hour after the start of aqueous phase chemistry, $\mathrm{O} / \mathrm{C}$ in the aqueous phase has remained around 1.0 and $n_{C}$ has decreased to 2.8 after a sharp initial increase to 2.9 , thus showing that fragmentation is a major process. This result is in good agreement with other aqueous phase studies (BrégonzioRozier et al., 2016; Epstein and Nizkorodov, 2012; Epstein et al., 2013) and other models (Schrödner et al., 2014), but is in disagreement with field studies, probably due to 


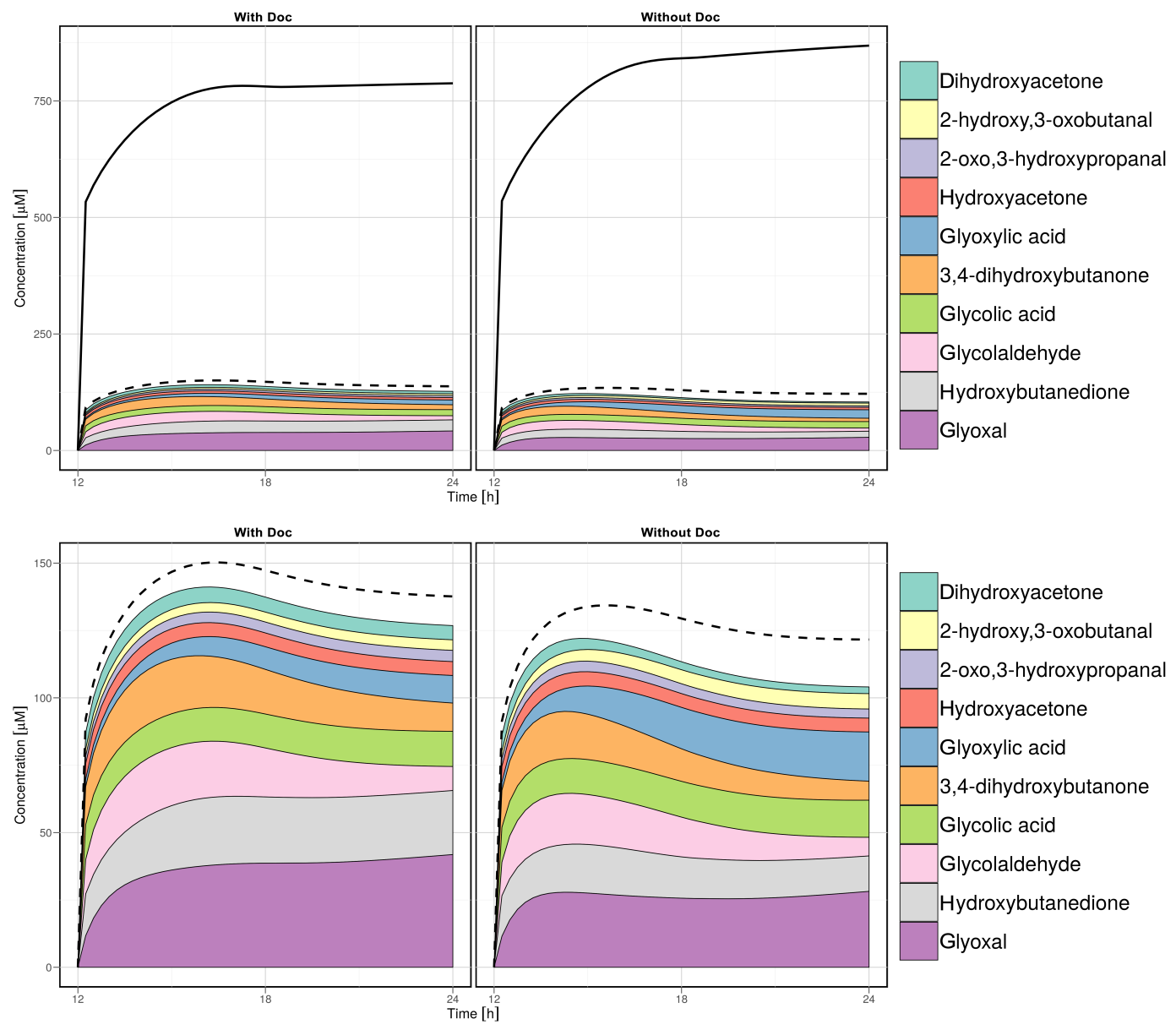

Figure 5. Contribution of the 10 most important species (in terms of concentrations) in the aqueous phase (colors). The solid line depicts the total concentration of dissolved organic compounds. The dashed line depicts the total concentration of reactive dissolved species.

a lack of descriptions of high molecular weight substances, and of their reactivity, as well as oligomerization processes. The higher O / C ratios obtained by Schrödner et al. (2014) after the cloud event (1.8 for their rural case) can be due to important oxalic acid concentrations dissolved into the aqueous phase in their model, when the cloud is being formed. At the end of our simulation, the reactive aqueous phase is composed of species with an average carbon skeleton of approximately 2.7 carbon atoms and an $\mathrm{O} / \mathrm{C}$ ratio of 1.1. Large molecules with high functionalization are statistically more soluble than smaller, less functionalized molecules (Mouchel-Vallon et al., 2013; Raventos-Duran et al., 2010). Therefore, at the onset of the cloud, the larger and more oxygenated species are dissolved, explaining the sharp increase in aqueous $n_{C}$ at the beginning of the cloud. In the gas phase, the $\mathrm{O} / \mathrm{C}$ ratio and $n_{C}$ follow a marked parabolic curve, reaching a maximum $\mathrm{O} / \mathrm{C}=0.8$ at 15:00 $\mathrm{LT}$ and a minimum $n_{C}=2.3$ at 14:00 LT. The $\mathrm{O} / \mathrm{C}$ ratio and $n_{C}$ then return to the cloud-free condition levels at sunset. During the day, cloud reactivity is responsible for the increasing $\mathrm{O} / \mathrm{C}$ ratios and decreasing $n_{C}$. These results suggest that our aqueous mechanism simulates an efficient fragmentation during the day, but again, our simulation does not take into account high molecular weight substances, their reactivity, as well as oligomerization processes that have been observed in field studies.

At the beginning of the cloud, many oxygenated and large compounds are dissolved, leading to an increase in the $\mathrm{O} / \mathrm{C}$ ratio and $n_{C}$ in the gas phase. Then, the reactivity in the aqueous phase generates smaller and more oxygenated species that desorb back to the gas phase, and the increase in the $\mathrm{O} / \mathrm{C}$ ratio is stronger than under clear-sky conditions. The observed effects of aqueous reactivity are confirmed by the addition of DOC, which leads to a slower increase in the $\mathrm{O} / \mathrm{C}$ ratio and a slower decrease in $n_{C}$ in both phases because lower $\mathrm{HO}$ radical concentrations result in a weaker oxidation capacity of the aqueous phase. 

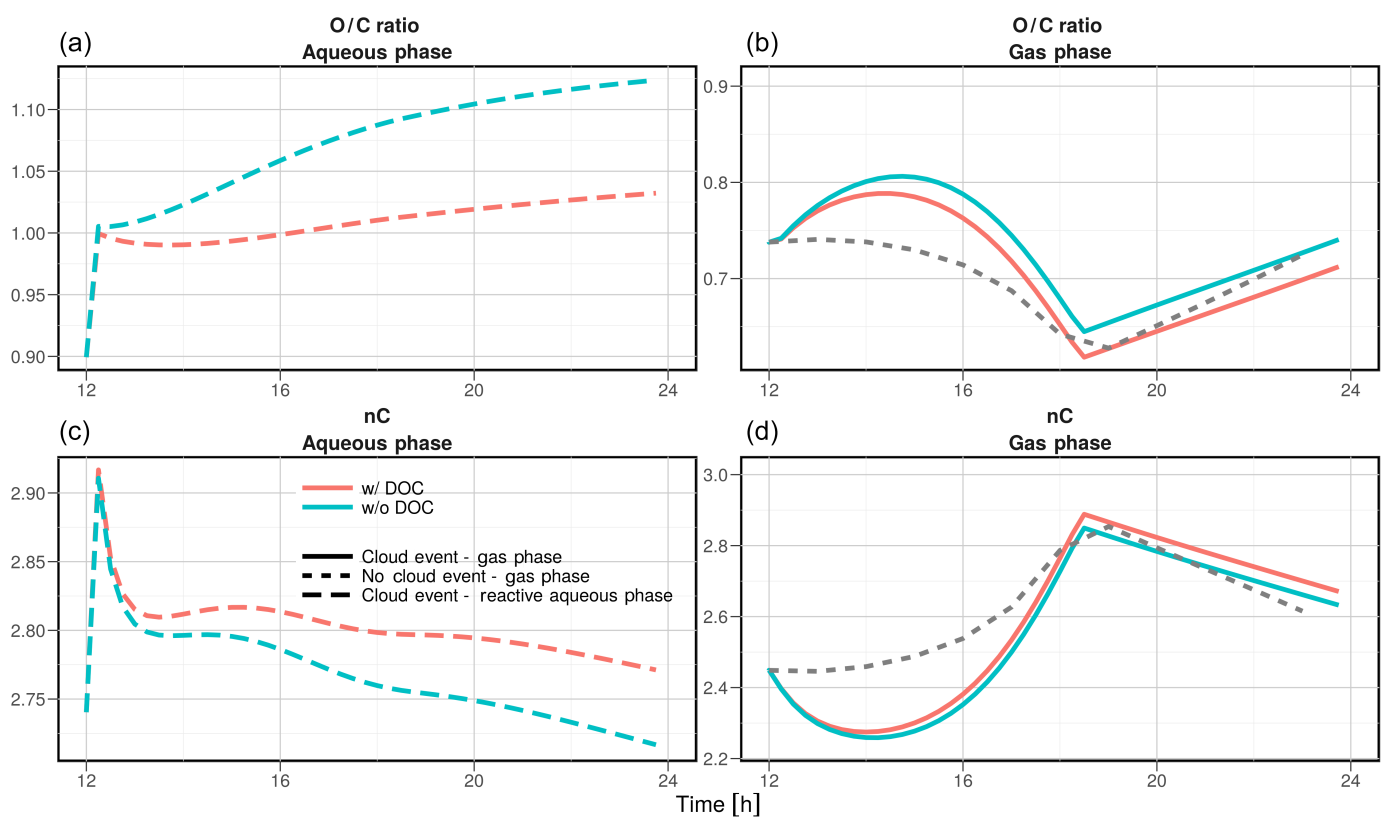

$(\mathrm{d})$

Gas phase

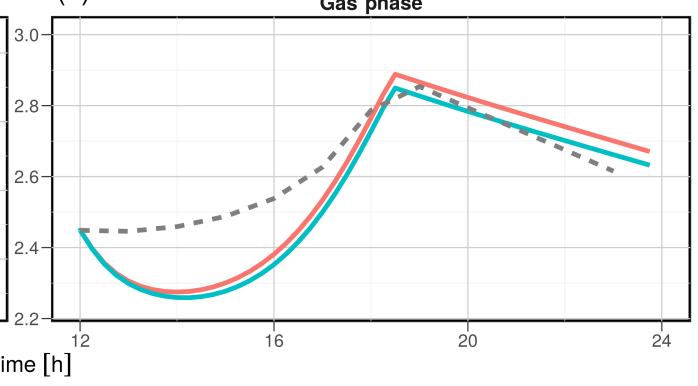

Figure 6. Time evolution of the mean $\mathrm{O} / \mathrm{C}$ ratio for the reactive species (top; ratios are calculated on a number of atoms basis; $\mathrm{CO}$, $\mathrm{CO}$, $\mathrm{CH}_{4}$, and iron-organic complexes are excluded from the calculation) and the mean number of carbon atoms $n_{\mathrm{C}}$ (bottom) in the aqueous phase (left) and in the gas phase (right) for the gas phase simulation (short dashed lines) and the cloud simulation (continuous lines). Cloud simulations are depicted with (red lines) and without (blue lines) DOC.

\section{Conclusions}

In this paper we described a new protocol with an explicit chemical scheme for aqueous phase oxidation. This protocol provides an up-to-date method to describe the dissolution of soluble VOCs, their hydration and/or acid dissociation equilibria (as well as iron-oxalate complexation), and their reactivity with $\mathrm{HO}$ or $\mathrm{NO}_{3}$ radicals. It was developed in cloud droplets and low- $\mathrm{NO}_{x}$ conditions and can be generalized to other, more polluted environments by introducing, for example, the multiphase reactivity of organonitrates. In this version, the mechanism includes alkanes, alcohols, carbonyls, carboxylic acids and hydroperoxides. The fate of the newly formed organic radicals is also addressed in detail. The protocol is applied to secondary organic species formed in the aqueous phase.

Under the simulated cloudy conditions, aqueous phase reactivity is shown to impact the $\mathrm{O} / \mathrm{C}$ ratio and the size of the secondary organic species, affecting the fragmentation and the functionalization processes resulting from atmospheric oxidation. Furthermore, the addition of a sink for dissolved organic matter shows that this impact on fragmentation and functionalization is sensitive to the aqueous phase oxidative capacity. These simulations were conducted for a permanent cloud. However, the mentioned results are atmospherically relevant, since the impact on the $\mathrm{O} / \mathrm{C}$ ratio and fragmentation can be observed in the first moments of the simulated cloud.
As long as the mechanism is used to simulate organic chemistry in cloud droplets, the hypotheses it is built on remain valid. However, modifications should be performed before applying the model to less dilute atmospheric aqueous phases, such as deliquescent aerosols. First, the non-ideality of such aqueous solutions should be taken into account. Second, $\mathrm{H}$-abstraction and $\mathrm{O}_{2}$-addition should be divided into two distinct steps, and accretion reactions should be considered (Renard et al., 2015). However, the first objective of this work is to thoroughly describe oxidation processes. Accretion processes will be accounted for in future versions of the mechanism.

This protocol is a powerful tool to explore and propose new reaction mechanisms as a basis for understanding experimental studies of scarcely investigated compounds. The mechanisms generated by our protocol can be used for different purposes in the study of atmospheric aqueous phase processes. They can be evaluated and adapted to laboratory experiments involving a small number of precursors that react only in the aqueous phase. The mechanisms are more likely to be useful for experiments involving multiphases in environmental cloud chambers (see for example BrégonzioRozier et al., 2016). They are also of interest for the modeling studies of field campaigns such as HCCT (Whalley et al., 2015) or SOAS (Nguyen et al., 2014). The SOA and the cloud chemistry communities are currently interested in studying the respective contributions of oxidation and accretion processes to the transformations of organic matter in the aqueous phase and to the oxidative capacity of clouds. 
Most recent modeling studies have focused on implementing newly identified accretion processes to evaluate their potential impacts on SOA formation (Ervens et al., 2015; McNeill, 2015; McNeill et al., 2012; Woo and McNeill, 2015). In this work, guidelines are developed to update oxidation mechanisms that will be compared in the future to descriptions of the formation of accretion products, such as oligomers, organonitrates and organosulfates.

Code availability. The mechanism used in this paper is available in KPP format upon request to 1.deguillaume@opgc.univbpclermont.fr. Any suggestions and corrections to the mechanism (e.g., a new experimental rate constant we may have missed, typos) are also welcomed at the same address. The modified version of DSMACC (originally downloaded at https://github.com/barronh/ DSMACC) that was used for the simulations is also available upon request to 1.deguillaume@opgc.univ-bpclermont.fr.

\section{The Supplement related to this article is available online at doi:10.5194/gmd-10-1339-2017-supplement.}

Competing interests. The authors declare that they have no conflict of interest.

Acknowledgements. The authors acknowledge French National Agency for Research (ANR) project CUMULUS ANR-2010BLAN-617-01 for providing financial support. The authors are very grateful to the Agence Nationale de la Recherche (ANR) for its financial support through the BIOCAP project (ANR-13-BS060004). Part of this work was also supported by CEA/CNRS through contract CEA 12-27-C-DSPG/CAJ - CNRS 77265.

Edited by: S. Bekki

Reviewed by: two anonymous referees

\section{References}

Alfassi, Z. B. (Ed.): The Chemistry of Free Radicals: Peroxyl Radicals, Wiley, New York, 1997.

Arakaki, T., Anastasio, C., Kuroki, Y., Nakajima, H., Okada, K., Kotani, Y., Handa, D., Azechi, S., Kimura, T., Tsuhako, A., and Miyagi, Y.: A general scavenging rate constant for reaction of hydroxyl radical with organic carbon in atmospheric waters, Environ. Sci. Technol., 47, 8196-8203, doi:10.1021/es401927b, 2013.

Asmus, K. D., Moeckel, H., and Henglein, A.: Pulse radiolytic study of the site of hydroxyl radical attack on aliphatic alcohols in aqueous solution, J. Phys. Chem., 77, 1218-1221, doi:10.1021/j100629a007, 1973.

Aumont, B., Szopa, S., and Madronich, S.: Modelling the evolution of organic carbon during its gas-phase tropospheric oxidation: development of an explicit model based on a self generating approach, Atmos. Chem. Phys., 5, 2497-2517, doi:10.5194/acp5-2497-2005, 2005.

Barth, M. C., Sillman, S., Hudman, R., Jacobson, M. Z., Kim, C. H., Monod, A., and Liang, J.: Summary of the cloud chemistry modeling intercomparison: Photochemical box model simulation, J. Geophys. Res., 108, 4214 , doi:10.1029/2002JD002673, 2003.

Benson, S. W.: Thermochemical Kinetics, Wiley, New York, 1976.

Blando, J. D. and Turpin, B. J.: Secondary organic aerosol formation in cloud and fog droplets: a literature evaluation of plausibility, Atmos. Environ., 34, 1623-1632, 2000.

Brégonzio-Rozier, L., Giorio, C., Siekmann, F., Pangui, E., Morales, S. B., Temime-Roussel, B., Gratien, A., Michoud, V., Cazaunau, M., DeWitt, H. L., Tapparo, A., Monod, A., and Doussin, J.-F.: Secondary organic aerosol formation from isoprene photooxidation during cloud condensation-evaporation cycles, Atmos. Chem. Phys., 16, 1747-1760, doi:10.5194/acp16-1747-2016, 2016.

Chameides, W. L.: The photochemistry of a remote marine stratiform cloud, J. Geophys. Res., 89, 4739-4755, 1984.

Chevallier, E., Jolibois, R. D., Meunier, N., Carlier, P., and Monod, A.: "Fenton-like" reactions of methylhydroperoxide and ethylhydroperoxide with $\mathrm{Fe}^{2+}$ in liquid aerosols under tropospheric conditions, Atmos. Environ., 38, 921-933, doi:10.1016/j.atmosenv.2003.10.027, 2004.

Cooper, A. J. L. and Redfield, A. G.: Proton magnetic-resonance studies of alpha-keto acids, J. Biol. Chem., 250, 527-532, 1975.

Damian, V., Sandu, A., Damian, M., Potra, F., and Carmichael, G. R.: The kinetic preprocessor KPP-a software environment for solving chemical kinetics, Comput. Chem. Eng., 26, 1567-1579, 2002.

Darer, A. I., Cole-Filipiak, N. C., O'Connor, A. E., and Elrod, M. J.: Formation and stability of atmospherically relevant isoprene-derived organosulfates and organonitrates, Environ. Sci. Technol., 45, 1895-1902, doi:10.1021/es103797z, 2011.

Davidovits, P., Kolb, C. E., Williams, L. R., Jayne, J. T., and Worsnop, D. R.: Mass accommodation and chemical reactions at gas-liquid interfaces, Chem. Rev., 106, 1323-1354, 2006.

Davidovits, P., Kolb, C. E., Williams, L. R., Jayne, J. T., and Worsnop, D. R.: Mass accommodation and chemical reactions at gas-liquid interfaces, Chem. Rev, 111, doi:10.1021/cr100360b, 2011.

DeCosta, D. P. and Pincock, J. A.: Control of product distribution by Marcus type electron-transfer rates for the radical pair generated in benzylic ester photochemistry, J. Am. Chem. Soc., 111, 89488950, doi:10.1021/ja00206a045, 1989.

Deguillaume, L., Leriche, M., Monod, A., and Chaumerliac, N.: The role of transition metal ions on $\mathrm{HO}_{x}$ radicals in clouds: a numerical evaluation of its impact on multiphase chemistry, Atmos. Chem. Phys., 4, 95-110, doi:10.5194/acp-4-95-2004, 2004.

Deguillaume, L., Leriche, M., Desboeufs, K., Mailhot, G., George, C., and Chaumerliac, N.: Transition metals in atmospheric liquid phases: sources, reactivity, and sensitive parameters, Chem. Rev., 105, 3388-3431, doi:10.1021/cr040649c, 2005.

Deguillaume, L., Charbouillot, T., Joly, M., Vaïtilingom, M., Parazols, M., Marinoni, A., Amato, P., Delort, A.-M., Vinatier, V., Flossmann, A., Chaumerliac, N., Pichon, J. M., Houdier, S., Laj, P., Sellegri, K., Colomb, A., Brigante, M., and Mailhot, G.: 
Classification of clouds sampled at the puy de Dôme (France) based on $10 \mathrm{yr}$ of monitoring of their physicochemical properties, Atmos. Chem. Phys., 14, 1485-1506, doi:10.5194/acp-14-14852014, 2014

Djouad, R., Sportisse, B., and Audiffren, N.: Numerical simulation of aqueous-phase atmospheric models: use of a non-autonomous Rosenbrock method, Atmos. Environ., 36, 873-879, doi:10.1016/S1352-2310(01)00497-6, 2002.

Djouad, R., Michelangeli, D. V., and Gong, W.: Numerical solution for atmospheric multiphase models: Testing the validity of equilibrium assumptions, J. Geophys. Res., 108, 4602, doi:10.1029/2002JD002969, 2003.

Donahue, N. M., Kroll, J. H., Pandis, S. N., and Robinson, A. L.: A two-dimensional volatility basis set - Part 2: Diagnostics of organic-aerosol evolution, Atmos. Chem. Phys., 12, 615-634, doi:10.5194/acp-12-615-2012, 2012.

Doussin, J.-F. and Monod, A.: Structure-activity relationship for the estimation of $\mathrm{OH}$-oxidation rate constants of carbonyl compounds in the aqueous phase, Atmos. Chem. Phys., 13, 11625-11641, doi:10.5194/acp-13-11625-2013, 2013.

Emmerson, K. M. and Evans, M. J.: Comparison of tropospheric gas-phase chemistry schemes for use within global models, Atmos. Chem. Phys., 9, 1831-1845, doi:10.5194/acp-9-18312009, 2009.

Epstein, S. A. and Nizkorodov, S. A.: A comparison of the chemical sinks of atmospheric organics in the gas and aqueous phase, Atmos. Chem. Phys., 12, 8205-8222, doi:10.5194/acp-12-82052012, 2012.

Epstein, S. A., Tapavicza, E., Furche, F., and Nizkorodov, S. A.: Direct photolysis of carbonyl compounds dissolved in cloud and fog droplets, Atmos. Chem. Phys., 13, 9461-9477, doi:10.5194/acp-13-9461-2013, 2013

Ervens, B.: Modeling the processing of aerosol and trace gases in clouds and fogs, Chem. Rev., 115, 4157-4198, doi:10.1021/cr5005887, 2015.

Ervens, B., George, C., Williams, J. E., Buxton, G. V, Salmon, G. A., Bydder, M., Wilkinson, F., Dentener, F., Mirabel, P., Wolke, R., and Herrmann, H.: CAPRAM 2.4 (MODAC mechanism): An extended and condensed tropospheric aqueous phase mechanism and its application, J. Geophys. Res., 108, 4426, doi:10.1029/2002JD002202, 2003.

Ervens, B., Feingold, G., Frost, G. J., and Kreidenweis, S. M.: A modeling study of aqueous production of dicarboxylic acids: 1 . Chemical pathways and speciated organic mass production, J. Geophys. Res., 109, D15205, doi:10.1029/2003JD004387, 2004.

Ervens, B., Turpin, B. J., and Weber, R. J.: Secondary organic aerosol formation in cloud droplets and aqueous particles (aqSOA): a review of laboratory, field and model studies, Atmos. Chem. Phys., 11, 11069-11102, doi:10.5194/acp-1111069-2011, 2011.

Ervens, B., Renard, P., Tlili, S., Ravier, S., Clément, J.-L., and Monod, A.: Aqueous-phase oligomerization of methyl vinyl ketone through photooxidation - Part 2: Development of the chemical mechanism and atmospheric implications, Atmos. Chem. Phys., 15, 9109-9127, doi:10.5194/acp-15-9109-2015, 2015.

Evans, M. G. and Polanyi, M.: Inertia and driving force of chemical reactions, Trans. Faraday Soc., 34, 11-24, 1938.
Exner, M., Herrmann, H., and Zellner, R.: Rate constants for the reactions of the $\mathrm{NO}_{3}$ radical with $\mathrm{HCOOH} / \mathrm{HCOO}^{-}$ and $\mathrm{CH}_{3} \mathrm{COOH} / \mathrm{CH}_{3} \mathrm{COO}^{-}$in aqueous solution between 278 and $328 \mathrm{~K}$, J. Atmos. Chem., 18, 359-378, doi:10.1007/BF00712451, 1994.

Farmer, D. K., Matsunaga, A., Docherty, K. S., Surratt, J. D., Seinfeld, J. H., Ziemann, P. J., and Jimenez, J. L.: Response of an aerosol mass spectrometer to organonitrates and organosulfates and implications for atmospheric chemistry, P. Natl. Acad. Sci. USA, 107, 6670-6675, doi:10.1073/pnas.0912340107, 2010.

Faust, B. C. and Zepp, R. G.: Photochemistry of aqueous iron(III)-polycarboxylate complexes: roles in the chemistry of atmospheric and surface waters, Environ. Sci. Technol., 27, 2517-2522, doi:10.1021/es00048a032, 1993.

Gaillard de Sémainville, P., Hoffmann, D., George, C., and Herrmann, H.: Study of nitrate radical $\left(\mathrm{NO}_{3}\right)$ reactions with carbonyls and acids in aqueous solution as a function of temperature, Phys. Chem. Chem. Phys., 9, 958-968, doi:10.1039/b613956f, 2007.

Gaillard de Sémainville, P., Anna, B. D., and George, C.: Aqueous phase reactivity of nitrate radicals $\left(\mathrm{NO}_{3}\right)$ toward dicarboxylic acids, Z. Phys. Chem., 224, 1247-1260, doi:10.1524/zpch.2010.6150, 2010.

Garnes, L. A. and Allen, D. T.: Size Distributions of organonitrates in ambient aerosol collected in Houston, Texas, Aerosol Sci. Technol., 36, 983-992, doi:10.1080/0278682029009218, 2002.

Giulianelli, L., Gilardoni, S., Tarozzi, L., Rinaldi, M., Decesari, S., Carbone, C., Facchini, M. C., and Fuzzi, S.: Fog occurrence and chemical composition in the Po valley over the last twenty years, Atmos. Environ., 98, 394-401, doi:10.1016/j.atmosenv.2014.08.080, 2014.

Graedel, T. E. and Weschler, C. J.: Chemistry within aqueous atmospheric aerosols and raindrops, Rev. Geophys., 19, 505539, doi:10.1029/RG019i004p00505, 1981.

Griffith, E. C., Carpenter, B. K., Shoemaker, R. K., and Vaida, V.: Photochemistry of aqueous pyruvic acid, P. Natl. Acad. Sci USA, 110, 11714-11719, doi:10.1073/pnas.1303206110, 2013.

Heald, C. L., Kroll, J. H., Jimenez, J. L., Docherty, K. S., DeCarlo, P. F., Aiken, A. C., Chen, Q., Martin, S. T., Farmer, D. K., and Artaxo, P.: A simplified description of the evolution of organic aerosol composition in the atmosphere, Geophys. Res. Lett., 37, L08803, doi:10.1029/2010GL042737, 2010.

Henon, E., Bohr, F., Chakir, A., and Brion, J.: Theoretical study of the methyl peroxy self-reaction: the intermediate structure, Chem. Phys. Lett., 264, 557-564, 1997.

Herckes, P., Valsaraj, K. T., and Collett, J. L.: A review of observations of organic matter in fogs and clouds: Origin, processing and fate, Atmos. Res., 132-133, 434-449, doi:10.1016/j.atmosres.2013.06.005, 2013.

Herckes, P., Marcotte, A. R., Wang, Y., and Collett, J. L.: Fog composition in the Central Valley of California over three decades, Atmos. Res., 151, 20-30, doi:10.1016/j.atmosres.2014.01.025, 2015.

Herrmann, H.: Kinetics of aqueous phase reactions relevant for atmospheric chemistry, Chem. Rev., 103, 4691-4716, 2003.

Herrmann, $\mathrm{H}$. and Zellner, R.: Reactions of $\mathrm{NO}_{3}^{-}$radicals in aqueous solution, in N-Centered Radicals, Wiley, New York, 291-243, 1998. 
Herrmann, H., Reese, A., Ervens, B., Wicktor, F., and Zellner, R.: Laboratory and modelling studies of tropospheric multiphase conversions involving some $\mathrm{C} 1$ and $\mathrm{C} 2$ peroxyl radicals, Phys. Chem. Earth Pt. B, 24, 287-290, 1999.

Herrmann, H., Ervens, B., Jacobi, H. W., Wolke, R., Nowacki, P., and Zellner, R.: CAPRAM2.3: A chemical aqueous phase radical mechanism for tropospheric chemistry, J. Atmos. Chem., 36, 231-284, 10.1023/a:1006318622743, 2000.

Herrmann, H., Tilgner, A., Barzaghi, P., Majdik, Z., Gligorovski, S., Poulain, L., and Monod, A.: Towards a more detailed description of tropospheric aqueous phase organic chemistry: CAPRAM 3.0, Atmos. Environ., 39, 4351-4363, doi:10.1016/j.atmosenv.2005.02.016, 2005.

Herrmann, H., Hoffmann, D., Schaefer, T., Bräuer, P., and Tilgner, A.: Tropospheric aqueous-phase free-radical chemistry: radical sources, spectra, reaction kinetics and prediction tools, Chemphyschem, 11, 3796-3822, doi:10.1002/cphc.201000533, 2010.

Herrmann, H., Schaefer, T., Tilgner, A., Styler, S. A., Weller, C., Teich, M., and Otto, T.: Tropospheric aqueous-phase chemistry: Kinetics, mechanisms, and its coupling to a changing gas phase, Chem. Rev., 115, 4259-4334, doi:10.1021/cr500447k, 2015.

Hilal, S. H., Ayyampalayam, S. N., and Carreira, L. A.: Air-liquid partition coefficient for a diverse set of organic compounds: Henry's law constant in water and hexadecane, Environ. Sci. Technol., 42, 9231-9236, 2008.

Hilborn, J. W. and Pincock, J. A.: Rates of decarboxylation of acyloxy radicals formed in the photocleavage of substituted 1naphthylmethyl alkanoates, J. Am. Chem. Soc., 113, 2683-2686, doi:10.1021/ja00007a049, 1991.

Hoffmann, D., Weigert, B., Barzaghi, P., and Herrmann, H.: Reactivity of poly-alcohols towards $\mathrm{OH}, \mathrm{NO}_{3}$ and $\mathrm{SO}_{4}^{-}$in aqueous solution, Phys. Chem. Chem. Phys., 11, 9351-9363, 2009

Hurley, T. J., Carrell, H. L., Gupta, R. K., Schwartz, J., and Glusker, J. P.: The structure of sodium $\beta$-fluoropyruvate: A gem-diol, Arch. Biochem. Biophys., 193, 478-486, 1979.

Ilan, Y., Rabani, J., and Henglein, A.: Pulse radiolytic investigations of peroxy radicals produced from 2-propanol and methanol, J. Phys. Chem., 80, 1558-1562, doi:10.1021/j100555a008, 1976.

Ivanov, A. V., Trakhtenberg, S., Bertram, A. K., Gershenzon, Y. M., and Molina, M. J.: $\mathrm{OH}, \mathrm{HO}_{2}$, and ozone gaseous diffusion coefficients, J. Phys. Chem. A, 111, 1632-1637, 2007.

Jacob, D. J.: Chemistry of $\mathrm{OH}$ in remote clouds and its role in the production of formic acid and peroxymonosulfate, J. Geophys. Res., 91, 9807-9826, 1986.

Jenkin, M. E., Young, J. C., and Rickard, A. R.: The MCM v3.3.1 degradation scheme for isoprene, Atmos. Chem. Phys., 15, 11433-11459, doi:10.5194/acp-15-11433-2015, 2015.

Jimenez, J. L., Canagaratna, M. R., Donahue, N. M., et al.: Evolution of organic aerosols in the atmosphere, Science, 326, 1525-1529, doi:10.1126/science.1180353, 2009.

Kaul, D. S., Gupta, T., Tripathi, S. N., Tare, V., and Collett, J. L.: Secondary Organic Aerosol: A Comparison between foggy and nonfoggy days, Environ. Sci. Technol., 45, 7307-7313, 2011.

Kirkland, J. R., Lim, Y. B., Tan, Y., Altieri, K. E., and Turpin, B. J.: Glyoxal secondary organic aerosol chemistry: Effects of dilute nitrate and ammonium and support for organic radical-radical oligomer formation, Environ. Chem., 10, 158-166, 2013.
Kozlowski, J. and Zuman, P.: Polarographic-reduction of aldehydes and ketones, Effects of acid-base, hydration dehydration and keto enol equilibria on reduction of alpha-ketoglutaric and oxalacetic acid and their esters, J. Electroanal. Chem., 226, 69-102, 1987.

Lee, A. K. Y., Herckes, P., Leaitch, W. R., Macdonald, A. M., and Abbatt, J. P. D.: Aqueous $\mathrm{OH}$ oxidation of ambient organic aerosol and cloud water organics: Formation of highly oxidized products, Geophys. Res. Lett., 38, L11805, doi:10.1029/2011GL047439, 2011.

Lee, A. K. Y., Hayden, K. L., Herckes, P., Leaitch, W. R., Liggio, J., Macdonald, A. M., and Abbatt, J. P. D.: Characterization of aerosol and cloud water at a mountain site during WACS 2010: secondary organic aerosol formation through oxidative cloud processing, Atmos. Chem. Phys., 12, 7103-7116, doi:10.5194/acp-12-7103-2012, 2012.

Lee, B. H., Mohr, C., Lopez-Hilfiker, F. D., et al.: Highly functionalized organic nitrates in the southeast United States: Contribution to secondary organic aerosol and reactive nitrogen budgets, P. Natl. Acad. Sci. USA, 113, 1516-1521, doi:10.1073/pnas.1508108113, 2016.

Lelieveld, J. and Crutzen, P. J.: The role of clouds in tropospheric photochemistry, J. Atmos. Chem., 12, 229, doi:10.1007/BF00048075, 1991.

Leriche, M., Voisin, D., Chaumerliac, N., Monod, A., and Aumont, B.: A model for tropospheric multiphase chemistry: application to one cloudy event during the CIME experiment, Atmos. Environ., 34, 5015-5036, doi:10.1016/S1352-2310(00)00329-0, 2000.

Leriche, M., Deguillaume, L., and Chaumerliac, N.: Modeling study of strong acids formation and partitioning in a polluted cloud during wintertime, J. Geophys. Res., 108, 1984-2012, doi:10.1029/2002JD002950, 2003.

Leriche, M., Curier, R. L., Deguillaume, L., Caro, D., Sellegri, K., and Chaumerliac, N.: Numerical quantification of sources and phase partitioning of chemical species in cloud: application to wintertime anthropogenic air masses at the Puy de Dôme station, J. Atmos. Chem., 57, 281-297, doi:10.1007/s10874-007-9073-y, 2007.

Lide, D. R. and Frederikse, H. P. R.: Handbook of Chemistry and physics, CRC Press, 1995.

Lim, Y. B., Tan, Y., and Turpin, B. J.: Chemical insights, explicit chemistry, and yields of secondary organic aerosol from $\mathrm{OH}$ radical oxidation of methylglyoxal and glyoxal in the aqueous phase, Atmos. Chem. Phys., 13, 8651-8667, doi:10.5194/acp13-8651-2013, 2013.

Liu, Y., El Haddad, I., Scarfogliero, M., Nieto-Gligorovski, L., Temime-Roussel, B., Quivet, E., Marchand, N., Picquet-Varrault, B., and Monod, A.: In-cloud processes of methacrolein under simulated conditions - Part 1: Aqueous phase photooxidation, Atmos. Chem. Phys., 9, 5093-5105, doi:10.5194/acp-9-50932009, 2009.

Long, Y., Charbouillot, T., Brigante, M., Mailhot, G., Delort, A.-M., Chaumerliac, N., and Deguillaume, L.: Evaluation of modeled cloud chemistry mechanism against laboratory irradiation experiments: The $\mathrm{H}_{x} \mathrm{O}_{y}$ /iron/carboxylic acid chemical system, Atmos. Environ., 77, 686-695, doi:10.1016/j.atmosenv.2013.05.037, 2013. 
Madronich, S. and Calvert, J. G.: Permutation reactions of organic peroxy radicals in the troposphere, J. Geophys. Res., 95, 5697, doi:10.1029/JD095iD05p05697, 1990.

McElroy, W. J. and Waygood, S. J.: Oxidation of formaldehyde by the hydroxyl radical in aqueous solution, J. Chem. Soc. Faraday Trans., 87, 1513-1521, doi:10.1039/ft9918701513, 1991.

McNeill, V. F.: Aqueous Organic Chemistry in the Atmosphere: Sources and chemical processing of organic aerosols, Environ. Sci. Technol., 49, 1237-1244, doi:10.1021/es5043707, 2015.

McNeill, V. F., Woo, J. L., Kim, D. D., Schwier, A. N., Wannell, N. J., Sumner, A. J., and Barakat, J. M.: Aqueous-phase secondary organic aerosol and organosulfate formation in atmospheric aerosols: A modeling study, Environ. Sci. Technol., 46, 80758081, doi:10.1021/es3002986, 2012.

Meylan, W. M. and Howard, P. H.: Src's epi suite, v3.20, Syracuse Research Corporation: Syracuse, NY, 2000.

Minakata, D., Li, K., Westerhoff, P., and Crittenden, J.: Development of a group contribution method to predict aqueous phase hydroxyl radical $(\mathrm{HO})$ reaction rate constants, Environ. Sci. Technol., 43, 6220-6227, doi:10.1021/es900956c, 2009.

Monod, A. and Carlier, P.: Impact of clouds on the tropospheric ozone budget: Direct effect of multiphase photochemistry of soluble organic compounds, Atmos. Environ., 33, 4431-4446, 1999.

Monod, A. and Doussin, J. F.: Structure-activity relationship for the estimation of $\mathrm{OH}$-oxidation rate constants of aliphatic organic compounds in the aqueous phase: alkanes, alcohols, organic acids and bases, Atmos. Environ., 42, 7611-7622, doi:10.1016/j.atmosenv.2008.06.005, 2008.

Monod, A., Poulain, L., Grubert, S., Voisin, D., and Wortham, $\mathrm{H}$.: Kinetics of $\mathrm{OH}$-initiated oxidation of oxygenated organic compounds in the aqueous phase: new rate constants, structureactivity relationships and atmospheric implications, Atmos. Environ., 39, 7667-7688, doi:10.1016/j.atmosenv.2005.03.019, 2005

Monod, A., Chevallier, E., Durand-Jolibois, R., Doussin, J., Picquet-Varrault, B., and Carlier, P.: Photooxidation of methylhydroperoxide and ethylhydroperoxide in the aqueous phase under simulated cloud droplet conditions, Atmos. Environ., 41, 2412-2426, doi:10.1016/j.atmosenv.2006.10.006, 2007.

Mouchel-Vallon, C., Bräuer, P., Camredon, M., Valorso, R., Madronich, S., Herrmann, H., and Aumont, B.: Explicit modeling of volatile organic compounds partitioning in the atmospheric aqueous phase, Atmos. Chem. Phys., 13, 10231037, doi:10.5194/acp-13-1023-2013, 2013.

Nathanson, G. M., Davidovits, P., Worsnop, D. R., and Kolb, C. E.: Dynamics and kinetics at the gas-liquid interface, J. Phys. Chem., 100, 13007-13020, 1996.

Neta, P., Huie, R., and Ross, A.: Rate constants for reactions of peroxyl radicals in fluid solutions, J. Phys. Chem. Ref. Data, 19, 413-513, 1990.

Nguyen, T. B., Roach, P. J., Laskin, J., Laskin, A., and Nizkorodov, S. A.: Effect of humidity on the composition of isoprene photooxidation secondary organic aerosol, Atmos. Chem. Phys., 11, 6931-6944, doi:10.5194/acp-11-6931-2011, 2011.

Nguyen, T. K. V., Petters, M. D., Suda, S. R., Guo, H., Weber, R. J., and Carlton, A. G.: Trends in particle-phase liquid water during the Southern Oxidant and Aerosol Study, Atmos. Chem. Phys. 14, 10911-10930, doi:10.5194/acp-14-10911-2014, 2014.

Paulot, F., Crounse, J. D., Kjaergaard, H. G., Kroll, J. H., Seinfeld, J. H., and Wennberg, P. O.: Isoprene photooxidation: new insights into the production of acids and organic nitrates, Atmos. Chem. Phys., 9, 1479-1501, doi:10.5194/acp-9-1479-2009, 2009.

Perri, M. J., Seitzinger, S., and Turpin, B. J.: Secondary organic aerosol production from aqueous photooxidation of glycolaldehyde: Laboratory experiments, Atmos. Environ., 43, 1487-1497, doi:10.1016/j.atmosenv.2008.11.037, 2009.

Perrin, D. D., Dempsey, B., and Serjeant, E. P.: pKa Prediction for organic acids and bases, Chapman and Hall, 1981.

Perring, A. E., Pusede, S. E., and Cohen, R. C.: An observational perspective on the atmospheric impacts of alkyl and multifunctional nitrates on ozone and secondary organic aerosol, Chem. Rev., 113, 5848-5870, doi:10.1021/cr300520x, 2013.

Piesiak, A., Schuchmann, M. N., Zegota, H., and von Sonntag, C.: $\beta$-Hydroxyethylperoxyl radicals: a study of the $\gamma$-radiolysis and pulse radiolysis of ethylene in oxygenated aqueous solutions, $\mathrm{Z}$. Naturforsch., 39, 1262-1267, 1984.

Pocker, Y., Meany, J. E., Nist, B. J., and Zadorojny, C.: Reversible hydration of pyruvic acid, I. Equilibrium studies, J. Phys. Chem., 73, 2879-2882, 1969.

Poulain, L., Katrib, Y., Isikli, E., Liu, Y., Wortham, H., Mirabel, P., Le Calve, S., and Monod, A.: In-cloud multiphase behaviour of acetone in the troposphere: Gas uptake, Henry's law equilibrium and aqueous phase photooxidation, Chemosphere, 81, 312-320, 2010.

Raventos-Duran, T., Camredon, M., Valorso, R., Mouchel-Vallon, C., and Aumont, B.: Structure-activity relationships to estimate the effective Henry's law constants of organics of atmospheric interest, Atmos. Chem. Phys., 10, 7643-7654, doi:10.5194/acp10-7643-2010, 2010

Reed Harris, A. E., Ervens, B., Shoemaker, R. K., Kroll, J. A., Rapf, R. J., Griffith, E. C., Monod, A., and Vaida, V.: Photochemical kinetics of pyruvic acid in aqueous solution, J. Phys. Chem. A, 118, 8505-8516, doi:10.1021/jp502186q, 2014.

Renard, P., Siekmann, F., Salque, G., Demelas, C., Coulomb, B., Vassalo, L., Ravier, S., Temime-Roussel, B., Voisin, D., and Monod, A.: Aqueous-phase oligomerization of methyl vinyl ketone through photooxidation - Part 1: Aging processes of oligomers, Atmos. Chem. Phys., 15, 21-35, doi:10.5194/acp-1521-2015, 2015.

Rollins, A. W., Browne, E. C., Min, K.-E., Pusede, S. E., Wooldridge, P. J., Gentner, D. R., Goldstein, A. H., Liu, S., Day, D. A., Russell, L. M., and Cohen, R. C.: Evidence for $\mathrm{NO}_{x}$ control over nighttime SOA formation, Science, 337, 1210 1212, doi:10.1126/science.1221520, 2012.

Ruggaber, A., Dlugi, R., Bott, A., Forkel, R., Herrmann, H., and Jacobi, H.-W.: Modelling of radiation quantities and photolysis frequencies in the aqueous phase in the troposphere, Atmos. Environ., 31, 3137-3150, doi:10.1016/S1352-2310(97)00058-7, 1997.

Saunders, S. M., Pascoe, S., Johnson, A. P., Pilling, M. J., and Jenkin, M. E.: Development and preliminary test results of an expert system for the automatic generation of tropospheric VOC degradation mechanisms, Atmos. Environ., 37, 1723-1735, doi:10.1016/S1352-2310(03)00072-4, 2003. 
Schaefer, T., Schindelka, J., Hoffmann, D., and Herrmann, H.: Laboratory kinetic and mechanistic studies on the $\mathrm{OH}$-initiated oxidation of acetone in aqueous solution, J. Phys. Chem. A, 116, 6317-6326, doi:10.1021/jp2120753, 2012.

Schöne, L. and Herrmann, H.: Kinetic measurements of the reactivity of hydrogen peroxide and ozone towards small atmospherically relevant aldehydes, ketones and organic acids in aqueous solutions, Atmos. Chem. Phys., 14, 4503-4514, doi:10.5194/acp-14-4503-2014, 2014.

Schöne, L., Schindelka, J., Szeremeta, E., Schaefer, T., Hoffmann, D., Rudzinski, K. J., Szmigielski, R., and Herrmann, H.: Atmospheric aqueous phase radical chemistry of the isoprene oxidation products methacrolein, methyl vinyl ketone, methacrylic acid and acrylic acid-kinetics and product studies, Phys. Chem. Chem. Phys., 16, 6257-6272, doi:10.1039/c3cp54859g, 2014.

Schrödner, R., Tilgner, A., Wolke, R., and Herrmann, H.: Modeling the multiphase processing of an urban and a rural air mass with COSMO-MUSCAT, Urban Climate, 10, 720-731, doi:10.1016/j.uclim.2014.02.001, 2014.

Schuchmann, H.-P. and von Sonntag, C.: Methylperoxyl radicals: a study of the $\gamma$-radiolysis of methane in oxygenated aqueous solutions, Z. Naturforsch., 39, 217-221, 1984.

Schuchmann, M. N., Zegota, H., and von Sonntag, C.: Acetate peroxyl radicals, $\mathrm{O}_{2} \mathrm{CH}_{2} \mathrm{CO}_{2}^{-}$: a study on the $\gamma$-radiolysis and pulse radiolysis of acetate in oxygenated aqueous solutions, $\mathrm{Z}$. Naturforsch. Pt. B, 40, 215-221, 1985.

Schuchmann, M. N., Schuchmann, H. P., and Von Sonntag, C.: The pKa value of the (carboxymethyl)peroxyl radical: the Taft $\sigma^{*}$ constant of the $-\mathrm{CH}_{2} \mathrm{O}_{2}$ group, J. Phys. Chem., 93, 5320-5323, doi:10.1021/j100350a055, 1989.

Schwartz, S. E.: Mass-transport considerations pertinent to aqueous phase reactions of gases in liquid-water clouds, NATO ASI Ser., G6, 415471, 1986.

Stemmler, K. and von Gunten, U.: $\mathrm{OH}$ radical-initiated oxidation of organic compounds in atmospheric water phases: part 2. Reactions of peroxyl radicals with transition metals, Atmos. Environ., 34, 4253-4264, 2000.

Stockwell, W. R., Kirchner, F., Kuhn, M., and Seefeld, S.: A new mechanism for regional atmospheric chemistry modeling, J. Geophys. Res., 102, 25847-25879, doi:10.1029/97JD00848, 1997.

Tilgner, A. and Herrmann, H.: Radical-driven carbonyl-to-acid conversion and acid degradation in tropospheric aqueous systems studied by CAPRAM, Atmos. Environ., 44, 5415-5422, doi:10.1016/j.atmosenv.2010.07.050, 2010.

Tilgner, A., Bräuer, P., Wolke, R., and Herrmann, H.: Modelling multiphase chemistry in deliquescent aerosols and clouds using CAPRAM3.0i, J. Atmos. Chem., 70, 221-256, doi:10.1007/s10874-013-9267-4, 2013.
Tur'yan, Y. I.: Kinetics and Equilibrium of the DehydrationHydration and Recombination-Dissociation Reactions of Glyoxylic Acid Investigated by Electrochemical Methods, Croat. Chem. Acta, 71, 727-743, 1998.

van Pinxteren, D., Fomba, K. W., Mertes, S., Müller, K., Spindler, G., Schneider, J., Lee, T., Collett, J. L., and Herrmann, H.: Cloud water composition during HCCT-2010: Scavenging efficiencies, solute concentrations, and droplet size dependence of inorganic ions and dissolved organic carbon, Atmos. Chem. Phys., 16, 3185-3205, doi:10.5194/acp-16-3185-2016, 2016.

von Sonntag, C.: The chemical basis of radiation biology, Taylor $\&$ Francis, London, 1987.

von Sonntag, C. and Schuchmann, H.-P.: Peroxyl Radicals in Aqueous Solutions, in: The Chemistry of Free Radicals: Peroxyl Radicals, edited by: Alfassi, Z. B., Wiley, New York, 1997.

Weller, C., Horn, S., and Herrmann, H.: Effects of Fe(III)concentration, speciation, excitation-wavelength and light intensity on the quantum yield of iron(III)-oxalato complex photolysis, J. Photochem. Photobiol. A, 255, 41-49, doi:10.1016/j.jphotochem.2013.01.014, 2013a.

Weller, C., Horn, S., and Herrmann, H.: Photolysis of Fe(III) carboxylato complexes: $\mathrm{Fe}(\mathrm{II})$ quantum yields and reaction mechanisms, J. Photochem. Photobiol. A, 268, 24-36, doi:10.1016/j.jphotochem.2013.06.022, 2013 b.

Whalley, L. K., Stone, D., George, I. J., Mertes, S., van Pinxteren, D., Tilgner, A., Herrmann, H., Evans, M. J., and Heard, D. E.: The influence of clouds on radical concentrations: observations and modelling studies of $\mathrm{HO}_{x}$ during the Hill Cap Cloud Thuringia (HCCT) campaign in 2010, Atmos. Chem. Phys., 15, 3289-3301, doi:10.5194/acp-15-3289-2015, 2015.

Woo, J. L. and McNeill, V. F.: simpleGAMMA v1.0 - a reduced model of secondary organic aerosol formation in the aqueous aerosol phase (aaSOA), Geosci. Model Dev., 8, 1821-1829, doi:10.5194/gmd-8-1821-2015, 2015.

Zegota, H., Schuchmann, M. N., Schulz, D., and von Sonntag, C.: Acetonylperoxyl radicals, $\mathrm{CH}_{3} \mathrm{COCH}_{2} \mathrm{O}_{2}$ : A study on the $\gamma$ radiolysis and pulse radiolysis of acetone in oxygenated aqueous solutions, Z. Naturforsch., 41, 1015-1022, 1986.

Zellner, R., Exner, M., and Herrmann, H.: Absolute OH quantum yields in the laser photolysis of nitrate, nitrite and dissolved $\mathrm{H}_{2} \mathrm{O}_{2}$ at 308 and $351 \mathrm{~nm}$ in the temperature range $278-353 \mathrm{~K}$, J. Atmos. Chem., 10, 411-425, doi:10.1007/BF00115783, 1990.

Zellner, R., Herrmann, H., Exner, M., Jacobi, H., Raabe, G., and Reese, A.: Formation and Reactions of Oxidants in the Aqueous Phase, in: Heterogeneous and Liquid-Phase Processes, edited by: Warneck, P., Springer-Verlag, Berlin, 146-152, 1995.

Zhang, X., Chen, Z. M., and Zhao, Y.: Laboratory simulation for the aqueous $\mathrm{OH}$-oxidation of methyl vinyl ketone and methacrolein: significance to the in-cloud SOA production, Atmos. Chem. Phys., 10, 9551-9561, doi:10.5194/acp-10-9551-2010, 2010. 